\title{
PLUTONIUM INHALATION STUDIES
}

(A series of lectures given in Japan in 1969 at the invitation of the Japanese Atomic Energy Commission)

\author{
by \\ W. J. Bair \\ Biology Department \\ Environmental and Life Sciences Division
}

February 1970 


\section{PLUTONIUM INHALATION STUDIES}

\section{LECTURE 1 \\ TECHNOLOGY USED IN PLUTONIUM INHALATION STUDIES*}

\section{HISTORY OF PROGRAM}

Our plutonium inhalation program began in about 1955. In beginning the program, we had not yet developed techniques for exposing animals to radioactive aerosols, so we used intratracheal injections as a method for introducing the plutonium into the lungs of mice, rats, and dogs. However, in these first experiments, it quickly became apparent that intratracheal injection was a poor substitute for inhalation of aerosols, because the particulate material was highly concentrated in two or three lobes of the lung instead of being uniform1y dispersed. Therefore, we began development of techniques to expose animals to radioactive aerosols under controlled conditions.

In our inhalation program, we have generally followed the practice of doing preliminary type experiments on mice, rats, and more recently, hamsters. To facilitate extrapolation of the results of animal studies to man, we usually follow the rodent experiments with dog experiments. For this purpose we have established our own beagle dog colony so that we would have a reliable source of healthy, nearly parasite-free dogs for experiments.

In establishing our inhalation program, we made the decision that our point of interest would begin when the aerosol was deposited in the body. While knowledge of the quantitative aspects of deposition of inhaled aerosols is of considerable interest and importance, rather elaborate technology is required to make the necessary measurements. Further, because the deposition of particulate materials is highly variable depending upon factors such as the anatomy and size of the

* Principal Investigators: J. F. Park, B. O. Stuart,

D. H. Wilzard, W.J. Bair 
respiratory tract, respiratory rate and volume, etc., it is difficult to extrapolate the results from animal studies to the human, except in a qualitative way. Because of this decision we were able to initiate aerosol exposures much earlier than if we had first tried to develop methods to measure deposition. As a result, our long-term dog experiments have been in progress more than 10 years.

The objectives of our inhalation program are:

- Provide guidance for establishment of permissible limits by identifying and defining hazards of inhaled radionuclides.

- Develop therapeutic methods for removal of inhaled radionuclides.

These objectives are being met by experimentally determining the disposition of various forms of inhaled material in the body and the acute and chronic biological effects which may occur.

A number of fission products have been studied. These are identified in Table 1.1 .

TABLE 1.1. Completed Inhalation Studies in Mice, Rats, and Dogs

Radionuclide Retention and Distribution (Acute and Long Term) ${ }^{131} \mathrm{I}$ ${ }^{90} \mathrm{Sr}$

$106_{\mathrm{Ru}}$

${ }^{144} \mathrm{Ce}$

${ }^{147} \mathrm{Pm}$ $237 \mathrm{~Np}$
$\mathrm{I}_{2}, \mathrm{AgI}$, Stable $\mathrm{I}_{2}$

$$
\mathrm{SrSO}_{4}, \mathrm{SrO}, \mathrm{SrF}_{2}, \mathrm{SrHPO}_{4}
$$$$
\mathrm{SrTlO}_{3}, \mathrm{SrCO}_{3}
$$$$
\mathrm{RuO}_{2}
$$

$\mathrm{CeO}_{2}$

$\mathrm{Pm}_{2} \mathrm{O}_{3}, \mathrm{Pm}\left(\mathrm{ClO}_{4}\right)_{3}$

$\mathrm{Np}$ dust
$\mathrm{SrSO}_{4}$

$\mathrm{RuO}_{2}$

$\mathrm{CeO}_{2}$

$\mathrm{Pm}_{2} \mathrm{O}_{3}$

Other: Removal of ${ }^{144} \mathrm{CeO}_{2}$ with DTPA Effects of Cigarette Smoking on Lung Clearance 
Using mice, rats, and dogs, we have studied retention, distribution, and biological effects of inhaled ${ }^{131} \mathrm{I},{ }^{90} \mathrm{Sr}$, ${ }^{106} \mathrm{Ru},{ }^{144} \mathrm{Ce},{ }^{147} \mathrm{Pm}$, and ${ }^{237} \mathrm{~Np}$. Most of these studies have been phased out and current emphasis is in the four following areas:

- Plutonium and curium.

- Uranium.

- Lung biochemistry and cytology.

- Removal therapy.

The most extensive program involves plutonium. Studies of curium are just getting started. Another part of the program is concerned with problems associated with the uranium mining and milling industry. The long-term effects of combined exposure to uranium ore dust, radon daughters, diesel engine exhaust fumes, and tobacco smoke are being studied in hamsters and dogs. To understand some of the processes fundamental to the disposition and biological effects of inhaled particles, the biochemistry of the lung, particularly in regard to the biosynthesis of surfactant, is being investigated. Also, cellular reactions to inhaled particles are being examined quantitatively and morphologically using light and electron microscopy. Because we have firsthand knowledge of the toxicity of inhaled plutonium and other radionuclides, we are extremely interested in developing therapeutic procedures to remove them from the body.

The extent of our plutonium studies is shown in Table 1.2. These will be dealt with in more detail in subsequent lectures. The disposition of inhaled plutonium has been compared for several compounds and for several particle size aerosols. Acute and chronic effects of inhaled plutonium have been defined in clinical studies. A significant response has been the development of lung tumors. Lymphopenia and immunosuppression are other effects which have been of interest. These will be discussed in a later lecture. 


\section{TABLE 1.2. Plutonium Inhalation Studies}

1. Retention, Distribution and Excretion

$\mathrm{PuO}_{2}, \mathrm{Pu}\left(\mathrm{NO}_{3}\right)_{4}, \mathrm{PuF}_{4}$

Particle Size Effects

Biliary Excretion

${ }^{239} \mathrm{Pu}$ vs. ${ }^{241} \mathrm{Am}$

$\mathrm{Pu}$ Microspheres
2. Biological Effects (Acute and Long Term)

${ }^{239} \mathrm{Pu}\left(\mathrm{NO}_{3}\right)_{4}$

Lymphopenia

Immunology

Reticuloendothelia1

System

3. Removal Therapy

\section{INHALATION EXPOSURE LABORATORY}

To introduce you to our plutonium studies, something should be said about the laboratory in which the animal exposures are accomplished. We have not required an elaborate facility, although it would have been helpful and we are looking forward to our new laboratory. Our requirements have been reasonably satisfied by a laboratory area which is only partially isolated from the other work area. The ventilation of the exposure laboratory is designed so that the air pressure in the exposure laboratory is negative with respect to the other space in the building. The exhaust air from the room goes through an absolute filter. The exhaust from aerosol chambers in the glove boxes in which the aerosols are generated is filtered at the chamber, at the glove box, and again when it leaves the laboratory. However, the lowest air pressure is maintained in the aerosol chamber to minimize direct contamination of the room air. The laboratory is equipped with two air sampling systems. One provides a direct measurement of alpha radiation levels. The second is a high volume filter sampler. The filters are removed for counting in proportional counters. 
A fresh air breathing system supplies air to masks worn by personne1 when aerosols are being generated or when room air contamination is known or suspected. Radiation monitoring personnel are always available when radioactive aerosols are being handled. The air monitoring system and the fresh air breathing system are equipped with alarms in the event of an emergency condition. Floor contamination occurs occasionally, but heavy tar paper is usually placed on the floor before experiments are started so that clean up is relatively easy. AEROSOL EXPOSURE CHAMBERS AND GLOVE BOXES

To study inhaled plutonium in experimental animals, it is desirable to cause the deposition of plutonium in a manner closely simulating that which would occur in a human exposure to contaminated air. Also to minimize radiological hazards to the researcher and avoid numerous other problems, it is necessary to prevent external contamination of the experimental animal. This requires that the aerosol be introduced. to just the nasal and oral regions of the animal. This is done by using suitable containers to hold rodents and masks for dogs.

Chamber and Glove Boxes for Rodents

Figure 1.1 shows a series of aerosol chambers used for mice exposed daily to ${ }^{90} \mathrm{Sr}$. The external contamination of these animals was acceptable because the aerosol was very low level and could be cleaned up. However, because plutonium presents more difficult decontamination problems than ${ }^{90} \mathrm{Sr}$, such a chamber could not be used for plutonium inhalation experiments .

Instead, it was necessary to confine the aerosol to an inner chamber, through ports in the wall of which the rodents were allowed to inhale the aerosol. An example is shown in Figure 1.2. Mice were individually placed head first into 


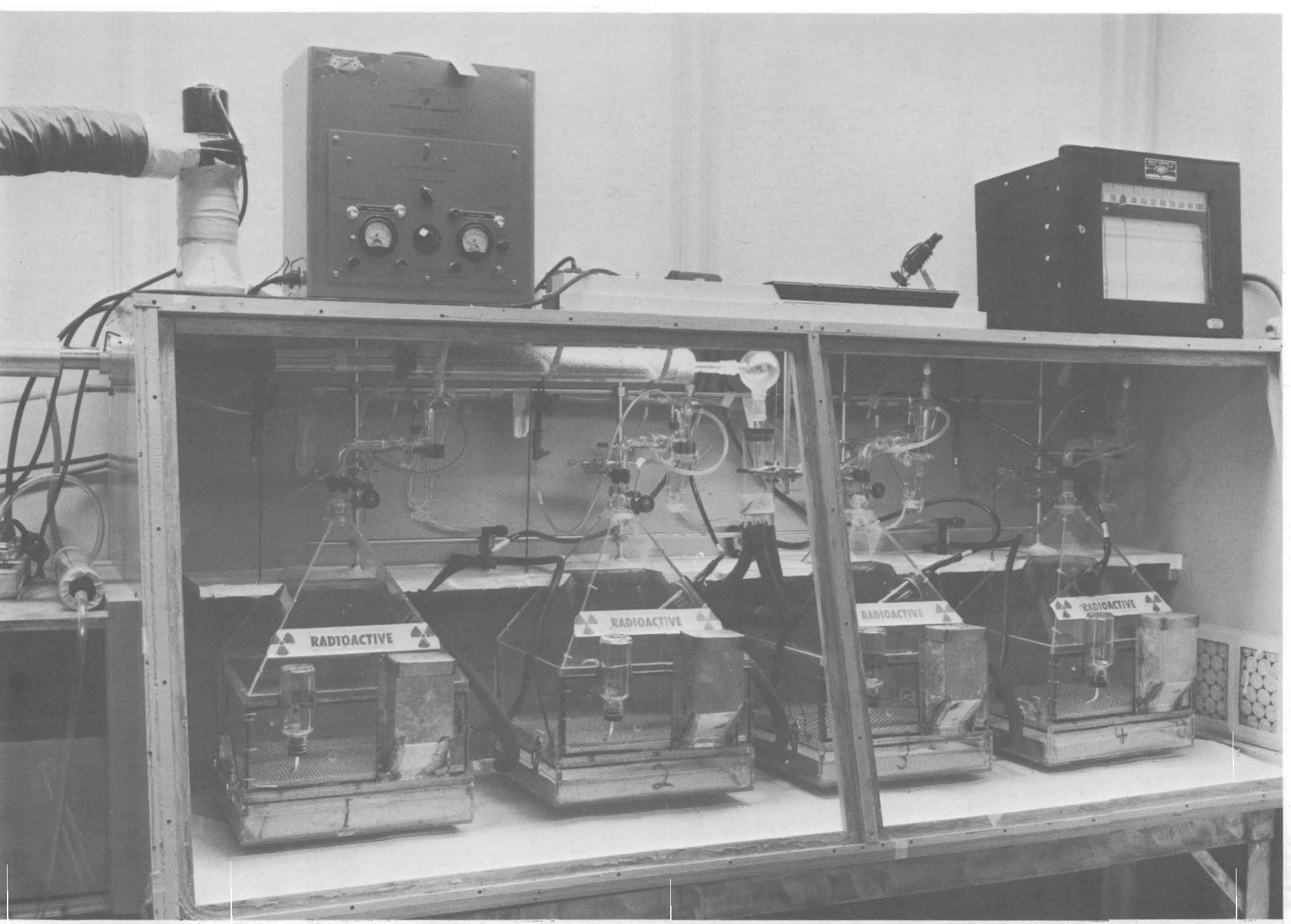

Neg 16733-11

FIGURE 1.1. Aerosol Exposure Chambers for Mice 


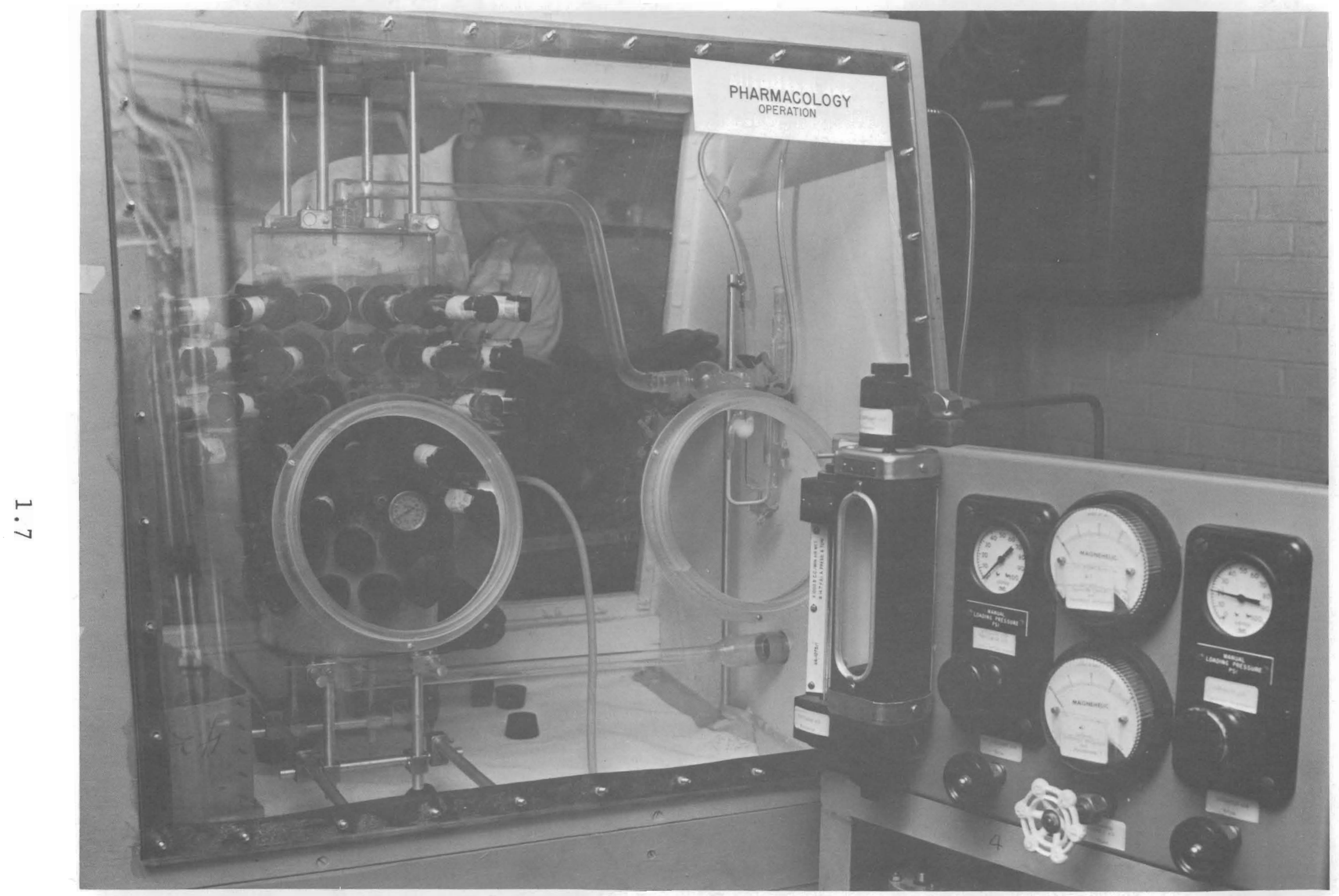

Neg 15789-1

FIGURE 1.2. Aerosol Exposure Chamber and Glove Box for Nose OnIy Exposure of Mice 
$50 \mathrm{~m} 1$ conical centrifuge tubes with the bottom $1 / 2$ in. cut off to give a 3/8-in. opening. The tubes containing the mice were inserted into ports drilled into the wall of a vertical aerosol chamber constructed of a 16-in. length of 8-in. (OD) lucite tubing. The exposure chamber could hold as many as 84 mouse tubes, in seven rows of 12 mice each row. The aerosol was admitted at the top and exhausted at the bottom through an electrostatic precipitator and two sets of membrane filters to collect plutonium and prevent contamination of the room air. In such a chamber, the aerosol concentration varied 25\% from top to bottom of the chamber.

Figure 1.3 shows a chamber and glove box used for rats. The principle is the same as for the mice except that it is slightly scaled up. Containers to hold rats were fabricated from Coca Cola bottles, the bottoms of which were removed with a glass saw. The rats were inserted through the bottoms of the bottles and held in place with large rubber stoppers. The bottles were then inserted into ports drilled into the wall of the aerosol chamber. Exposing mice and rats to radioactive aerosols in this manner restricted the radioactive contamination mainly to the head region. Following exposure to the aerosol, the heads of the rats were washed with water and detergent.

Another glove box and chamber used for exposure of rats to plutonium and other radionuclides are shown in Figure 1.4 . This is a relatively inexpensive glove box and is used for routine rat exposures. When they become heavily contaminated and there is difficulty in confining the contamination to the inside of the glove box, the boxes are sealed in a large wooden box and buried.

Figure 1.5 shows a more elaborate version of a glove box for exposing rats to radionuclides. The aerosol chamber is 
BNWL - 1221

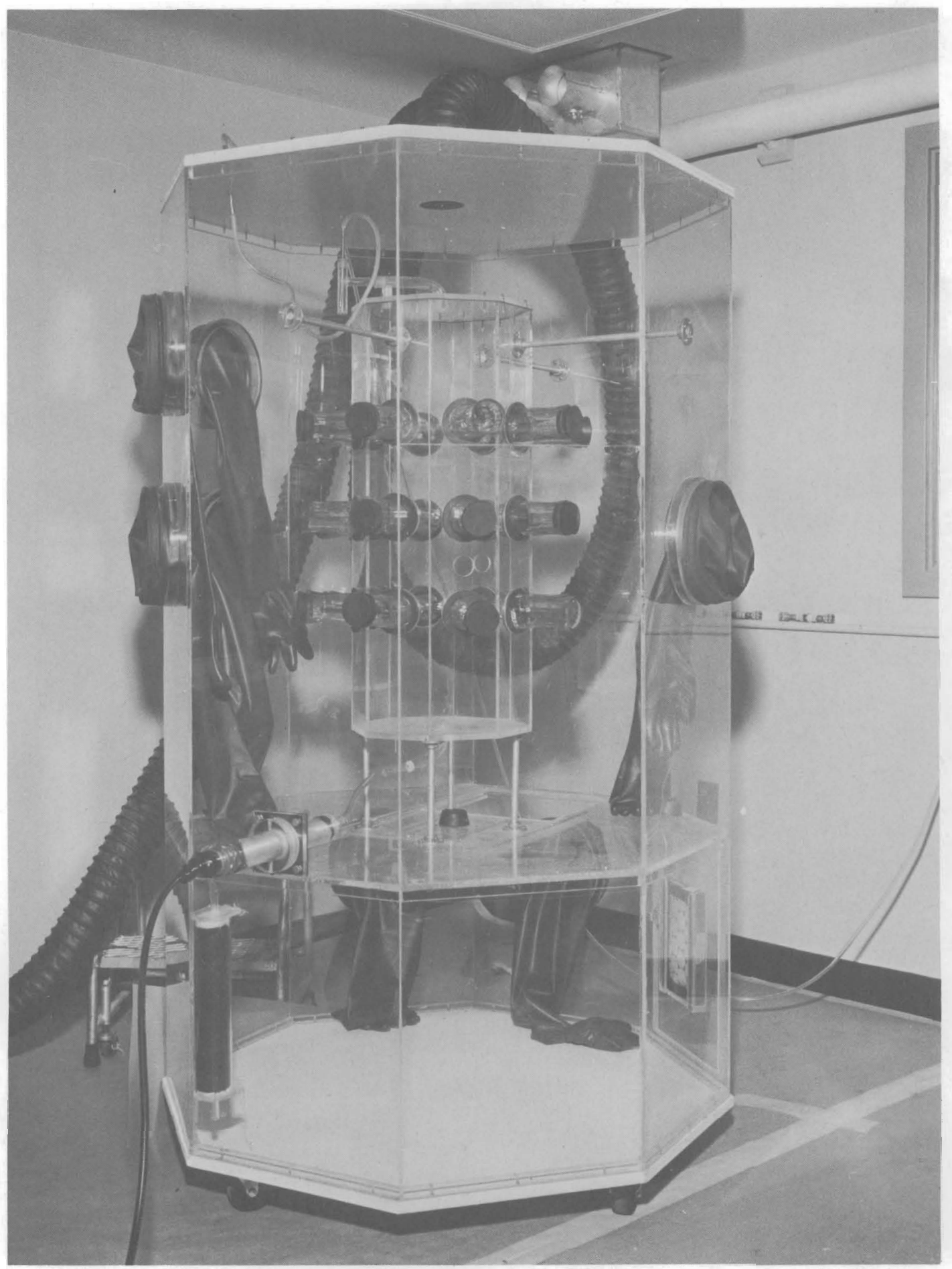

Neg $18779-2$

EIGURE 1.3. Aerosol Exposure Chamber and Glove Box for Nose only Exposure of Rats 


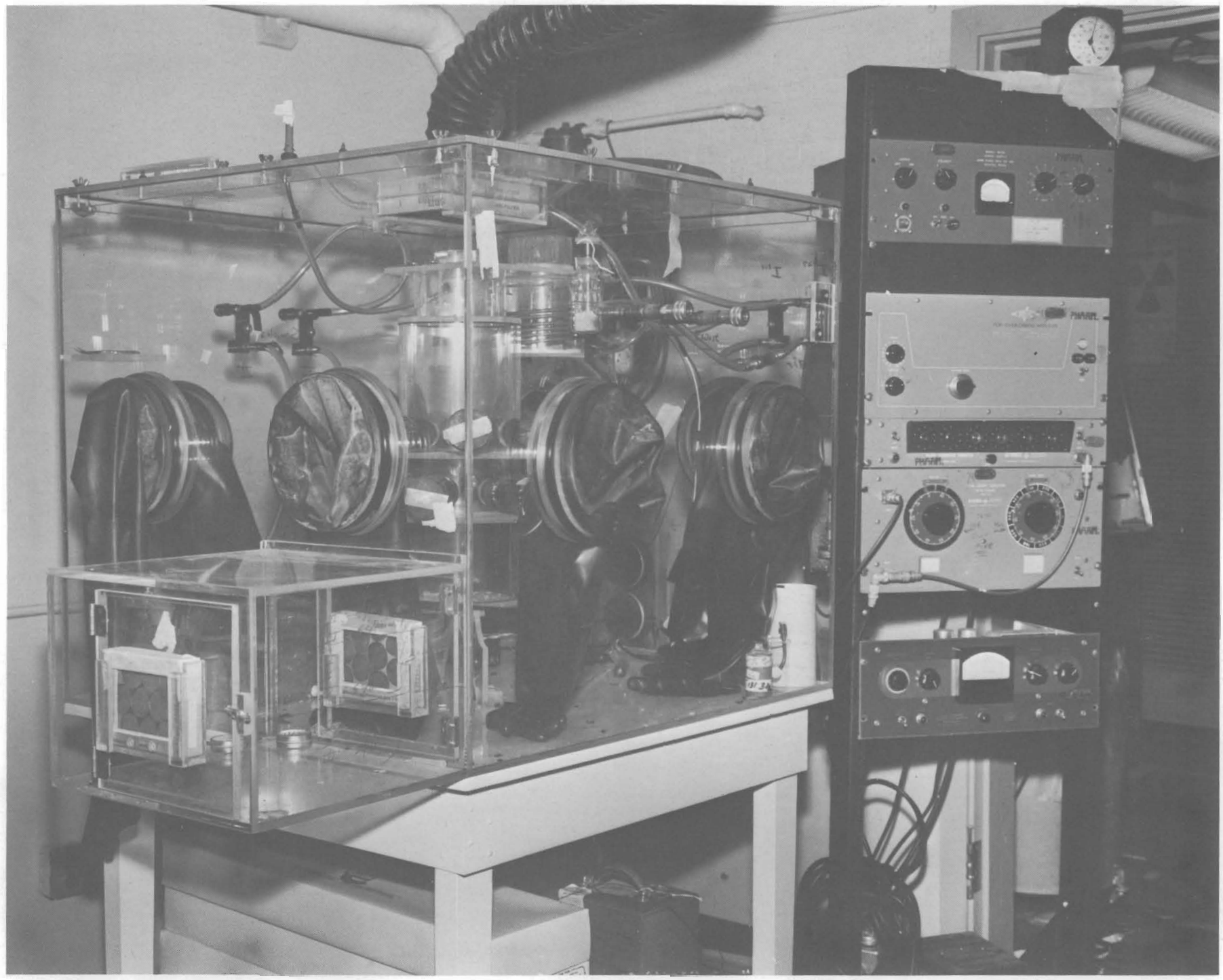

Neg 29715-10

FIGURE 1.4. Aerosol Exposure Chamber and Glove Box for Rats 
BNWL -1221

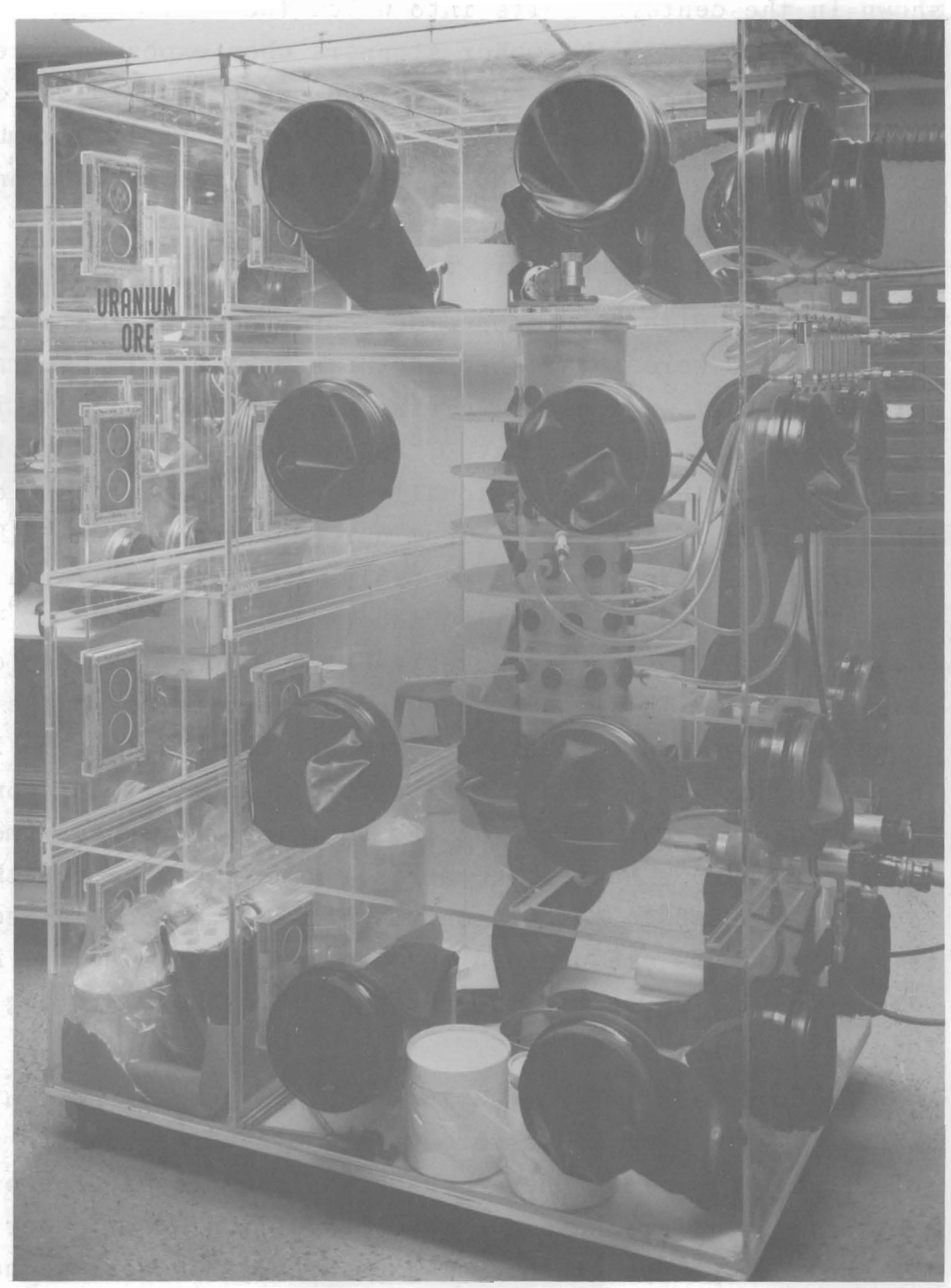

Neg 38997

FIGURE 1.5. GLove Box Containing Aerosol Exposure Chamber and Cage Storage Space for Rats 
shown in the center. Ports into which the bottled rats are placed are closed with rubber stoppers when exposures are not in progress. This glove box provided space for storage of waste. A dust generator is shown at the top of the chamber. Everything taken into or out of the box passes through an air lock. Electrostatic precipitators used to decontaminate the exhaust from the chamber are also shown.

Our work with ${ }^{238} \mathrm{Pu}$ posed serious potential contamination problems. We were interested in the acute lethal dose range. This meant that we would be giving each rat 50 to $100 \mu \mathrm{Ci}$. In addition we had learned that ${ }^{238} \mathrm{Pu}$ seemed to be more mobile than ${ }^{239} \mathrm{Pu}$ in that we occasionally found ${ }^{238} \mathrm{Pu}$ on the floor of the 1aboratory. This was seldom our experience with ${ }^{239} \mathrm{Pu}$. The explanation for this is probably the fact that for a given mass, ${ }^{238} \mathrm{Pu}$ is about 280 times more radioactive than ${ }^{239} \mathrm{Pu}$. Because of this, ${ }^{238} \mathrm{Pu}$ is more readily detected than an equal mass of ${ }^{239} \mathrm{Pu}$. This glove box was designed to house the rats as well as contain the aerosol exposure chamber (Figure 1.6). The glove box is divided into areas. The compartment containing the aerosol chamber is at one end. Another compartment above the chamber houses the aerosol generator. After the rats are exposed to the plutonium aerosol, the bottles containing the rats are dropped through the chute into the housing compartment. The bottles are dropped into the waste bag and the rats are put into cages.

We have been interested in using hamsters in our pulmonary studies. Rats and, to lesser extent, mice are prone to respiratory tract infection, whereas hamsters seem to be free of such problems. Hamsters have been successfully used at other sites for whole body type of aerosol exposures. However, we have had difficulty in confining them to soft drink bottles or other type containers. The hamsters are capable of reversing themselves in most types of such confinement, and can suffocate 


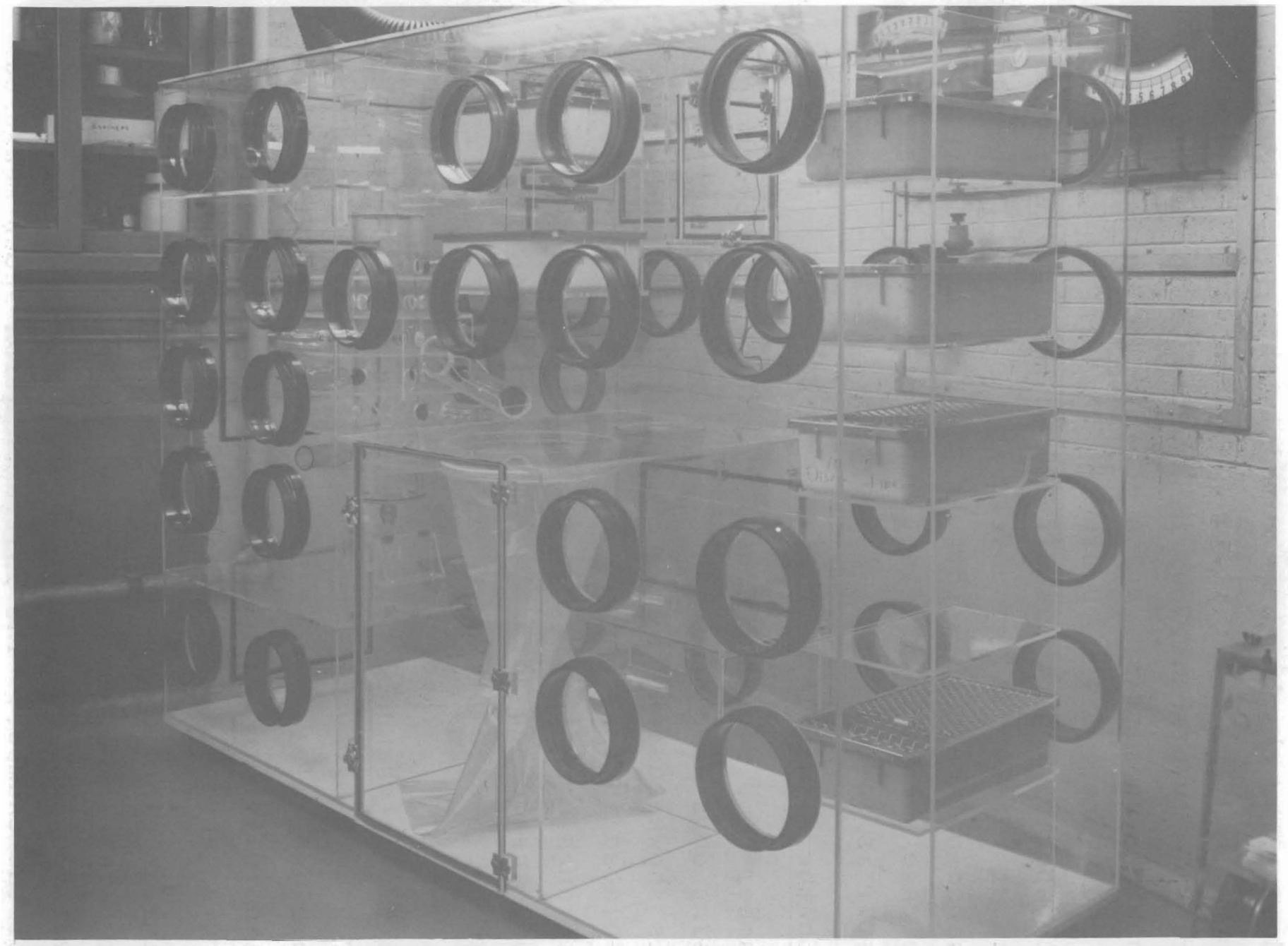

Neg 38997

FIGURE 1.6. Multi-Compartment Glove Box Containing Aerosol Exposure Chamber, Cage Storage Area, Radioactive Waste Storage, and Aerosol Generators for High Level Radionuclide Exposures of Rats 
in the bottles. Therefore, we have been trying to develop a hamster chamber for nose only type of exposure. Hamsters are being used in a study of inhaled radon, radon daughters, and uranium dust. The chamber being used in this project may interest you (Figure 1.7). It is comprised of two lucite hemispheres. A turntable floor is located at the equator. Cages containing hamsters are loaded into the chamber through the port and placed on the turntable. Excreta is collected on absorbent paper placed on a shelf below the cages. Aerosol is introduced at the top and exhausted at the bottom. The chamber can be washed out through a port in the bottom. Figure 1.8 shows the cage used. It is constructed of stainless steel. Each hamster is in a separate compartment.

Aerosol Chambers and Glove Boxes for Dogs

A number of different aerosol chambers and glove boxes for exposing dogs have evolved. In Figure 1.9, a large dust chamber is shown suspended in one compartment of the glove box. The dog, placed in the compartment to the right, inhaled the aerosol through a mask attached to the bottom of the tank. A plastic bag inside the aerosol chamber collapsed as the dog inhaled the aerosol. Dry dust can be fired into this chamber with an air pistol. There are also other ways of introducing dust into such a chamber. The technician is shown wearing a fresh-air breathing mask. The recorder is used to monitor temperature and relative humidity within the chamber. The relative humidity of the chamber seldom exceeds $40 \%$ even when aerosols are generated from aqueous solutions or suspensions.

A similar glove box is shown in Figure 1.10. However, a different aerosol chamber was used. It consisted of a large octagon with conical ends. The aerosol generator is shown at the top of the chamber. The instrumentation shown measured pressures and air flows within the system. 
BNWL - 1221

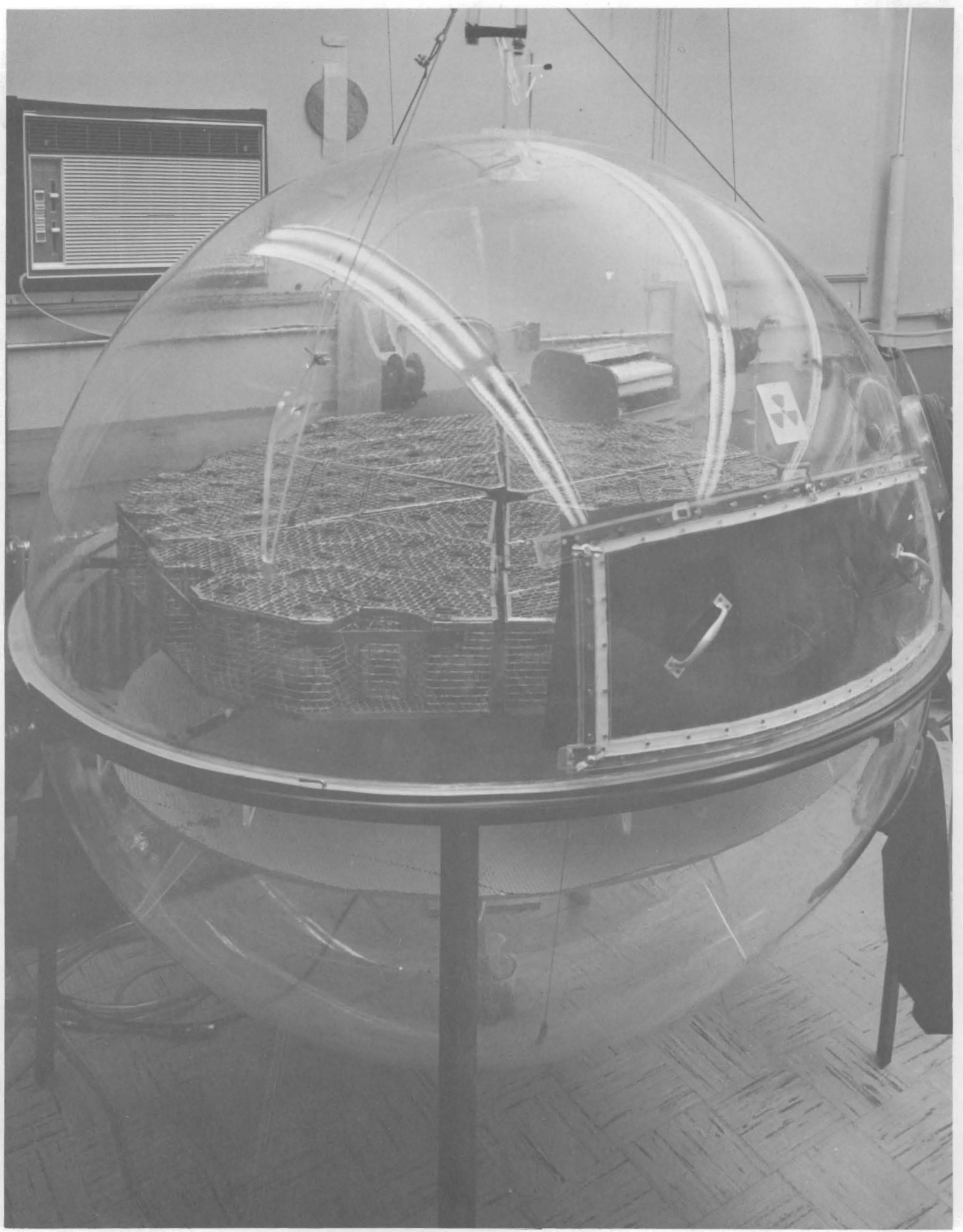

Neg $0690341-2$

FIGURE 1.7. Spherical Aerosol Chamber for Daily Exposure of Hamsters to Constituents of Uranium Mine Environment 
BNWL -1221

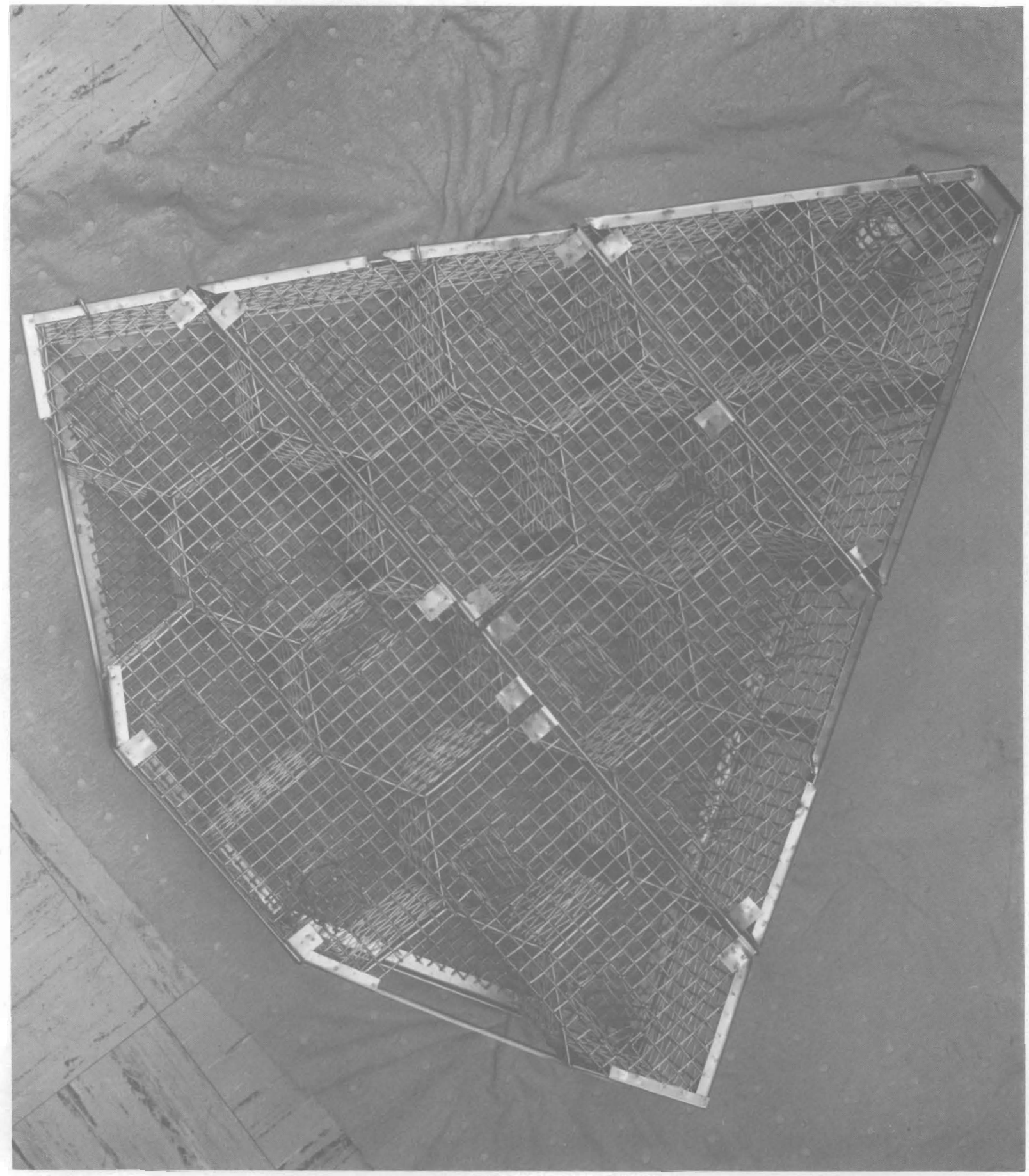

Neg 0690341-11

FIGURE 1.8. Hamster Cages for Spherical Aerosol Chamber 


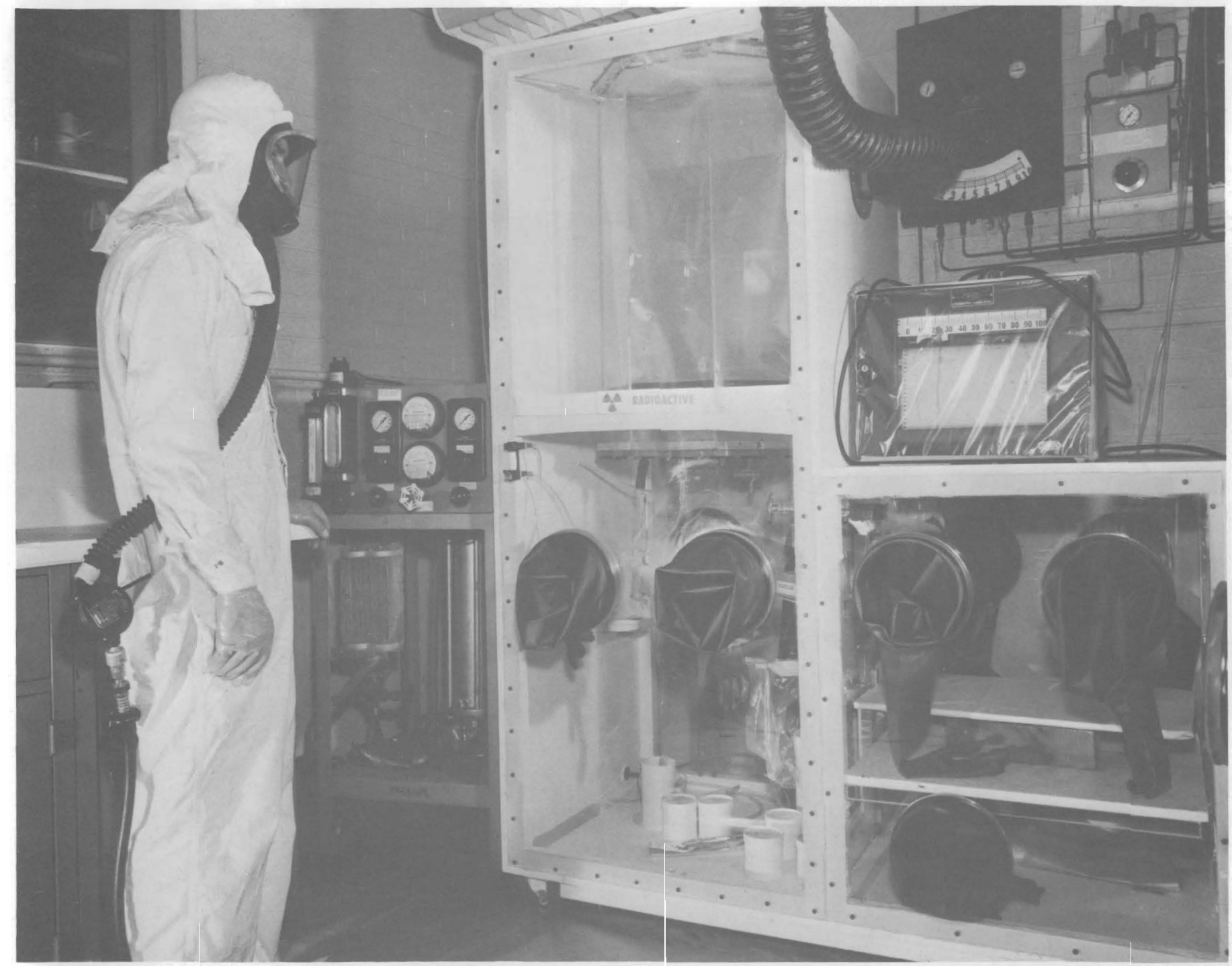

Neg $17649-3$

FIGURE 1.9. Glove Box and Aerosol Chamber for Exposure of Dogs (Plutonium dioxide dust was fixed into the aerosol chamber with an air pistol.) 


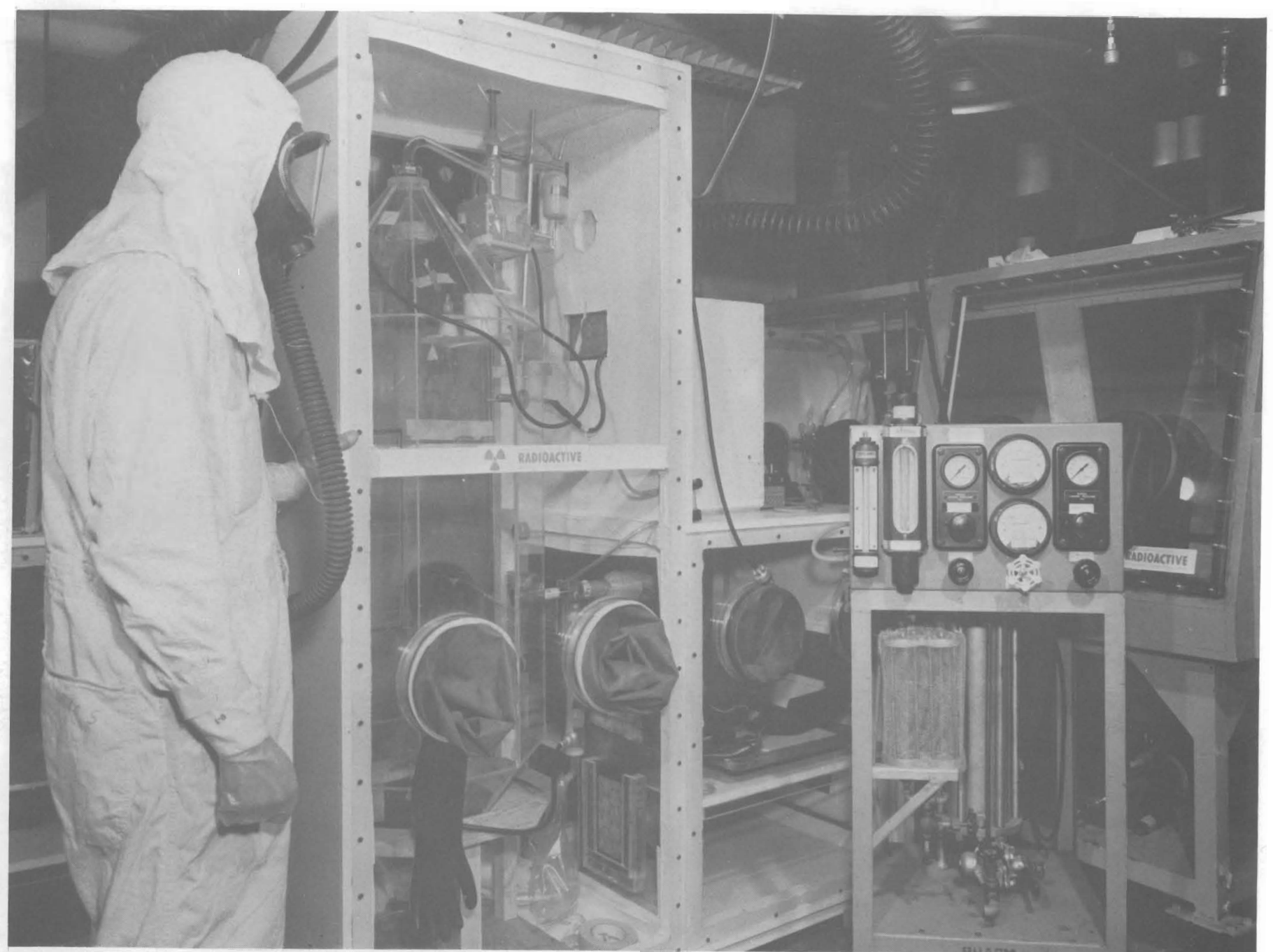

Neg 17649-4 conical top of the octagon chamber.) 
In those experiments where daily exposures of dogs were required, it was necessary to devise a system by which more than one dog could be exposed at one time. The glove box and chamber shown in Figure 1.11 accommodates five dogs simultaneously. The dogs are trained to sit in the boxes. The masks through which they inhale the aerosol are rigidly attached to the aerosol chamber, in this case a 3 -ft diameter hexagon.

The most recent design for an aerosol exposure system for dogs is shown in Figure 1.12. The aerosol chamber is contained in the large compartment of the glove box. The dog sits in another compartment with his nose in a mask. The mask is fabricated from liquid latex and plaster. It is attached to a three-way respiratory valve which is controlled by electronic circuits housed in the boxes above the dog. The floor upon which the dog sits can be altered by an electrically operated jack to keep the dog comfortable.

The aerosol generator is located in the compartment above the aerosol chamber. Air flows and pressure in the equipment are controlled at the console. Three 1-in. membrane filter samplers operate simultaneously, at about $100 \mathrm{~cm}^{3} / \mathrm{min}$. Thermal precipitators are used to sample the air exhaled by the dog as well as the air within the aerosol chamber for particle size measurements by electron microscopy. Air is exhausted from the aerosol chamber through an electrostatic precipitator and at least two membrane filters, at a rate of about $6 \mathrm{l} / \mathrm{min}$. This is a slight excess of the rate of air introduced through the aerosol-generating system to ensure that the pressure in the chamber is negative with respect to the glove box. Figure 1.13 shows a close-up of the respiratory valve which is attached to the aerosol chamber and the mask of the dog. The respiratory valve was a linear valve operated by a linear motor, Figure 1.14. 
BNWL - 1221

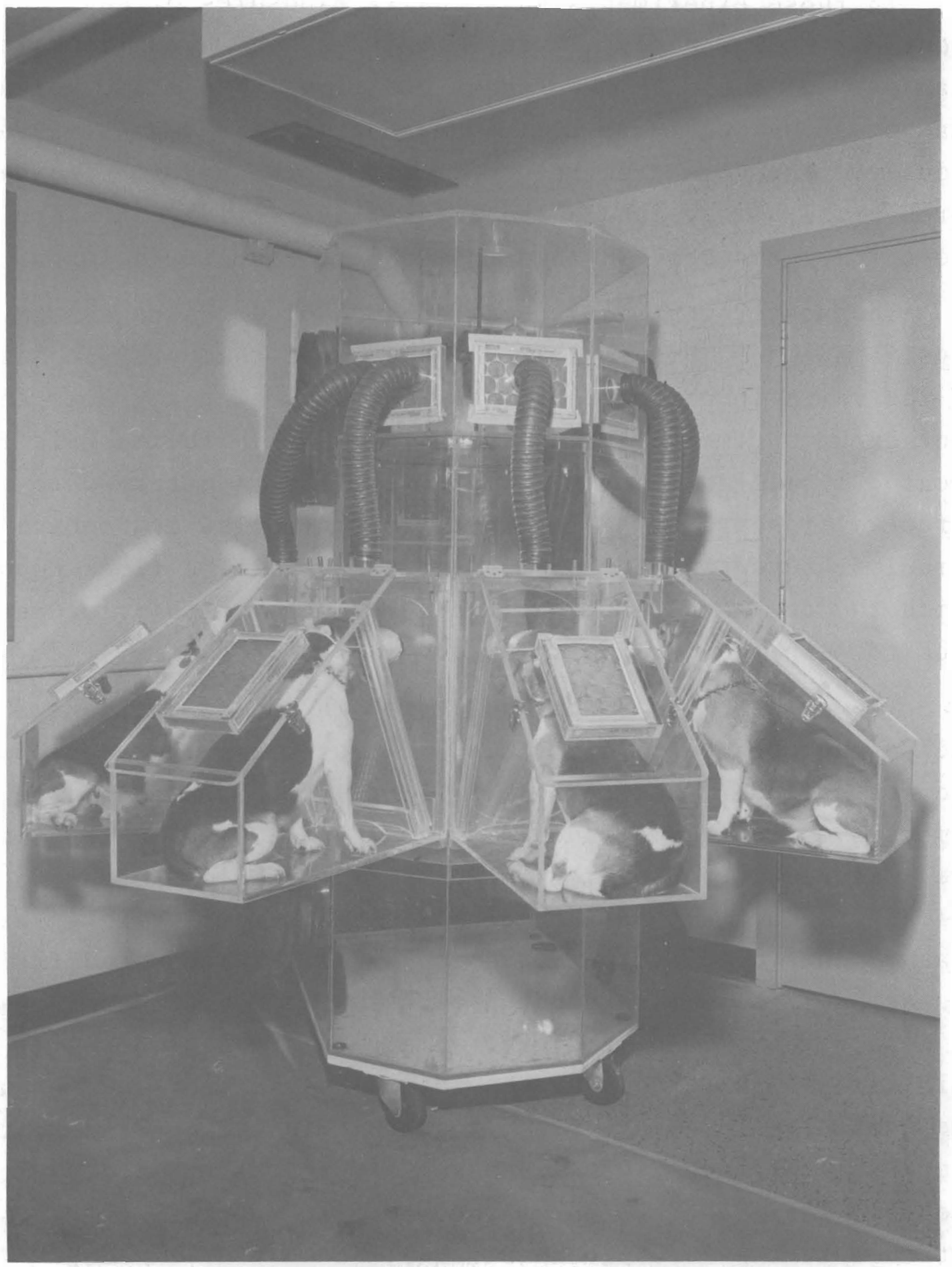

Neg $18779-3$

FIGURE 1.11. GZove Box and Aerosol Chamber for simultaneous Exposure of Five Dogs 


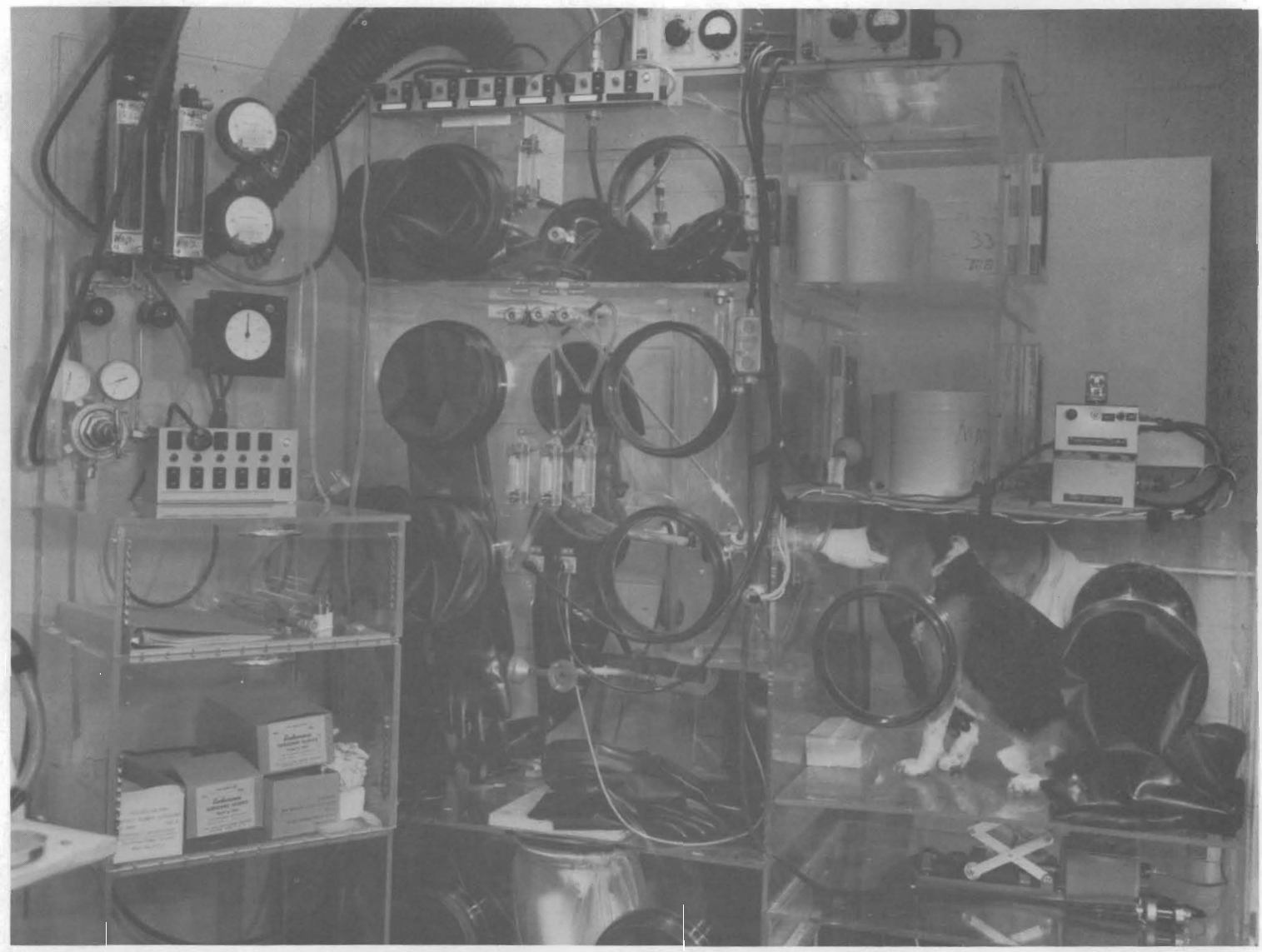

Neg 38997-?

FIGURE 1.12. GLove Box and Aerosol Chamber for Exposure of Dogs (Exposure of the dog occurs through a three-way respiratory valve. Respiratory rate and volume and exhaled air are measured.) 


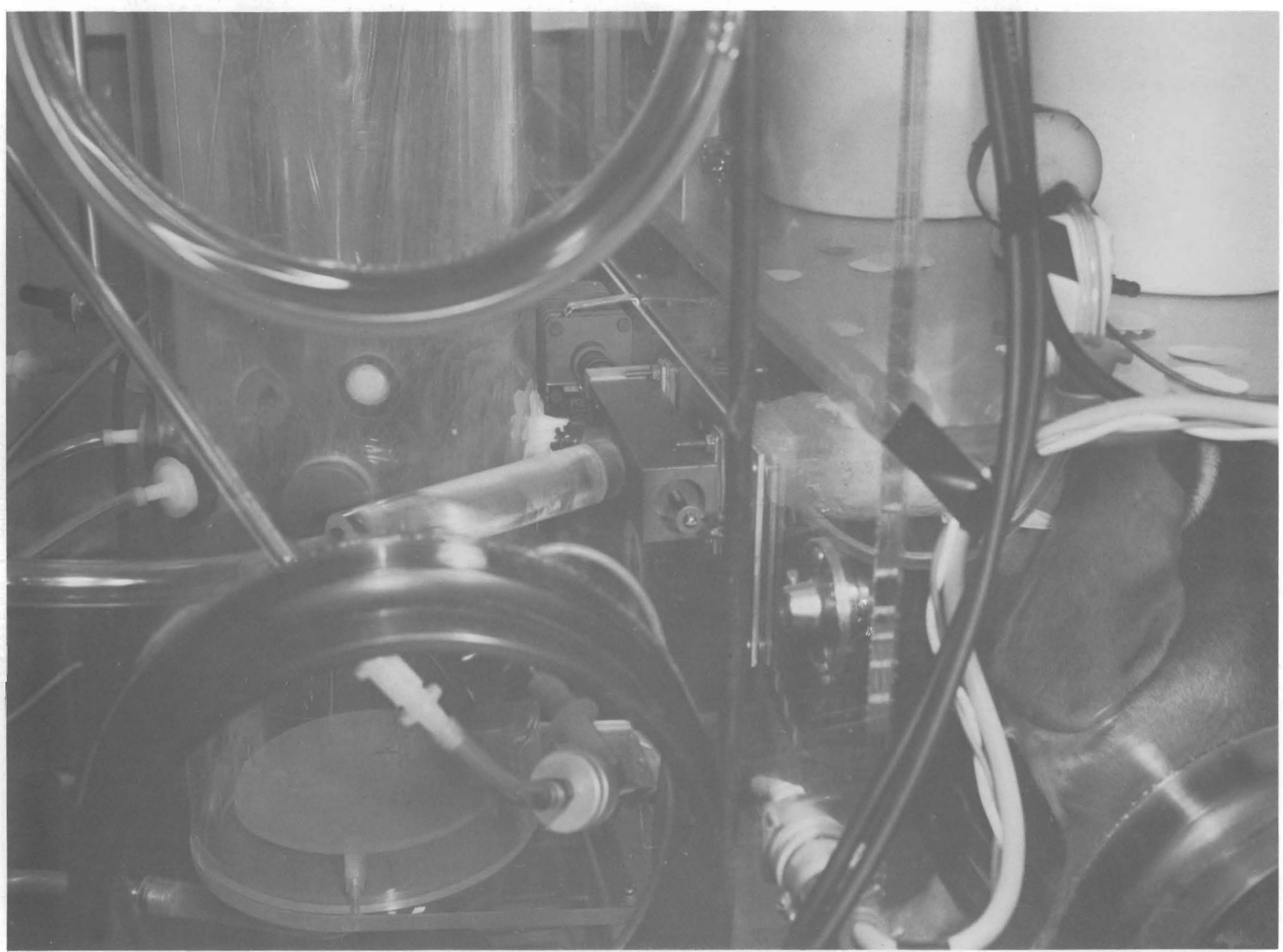

Neg 38997-6

FIGURE 1.13. Three-Way Respiratory Valve for Exposure of Dogs to Radio- 


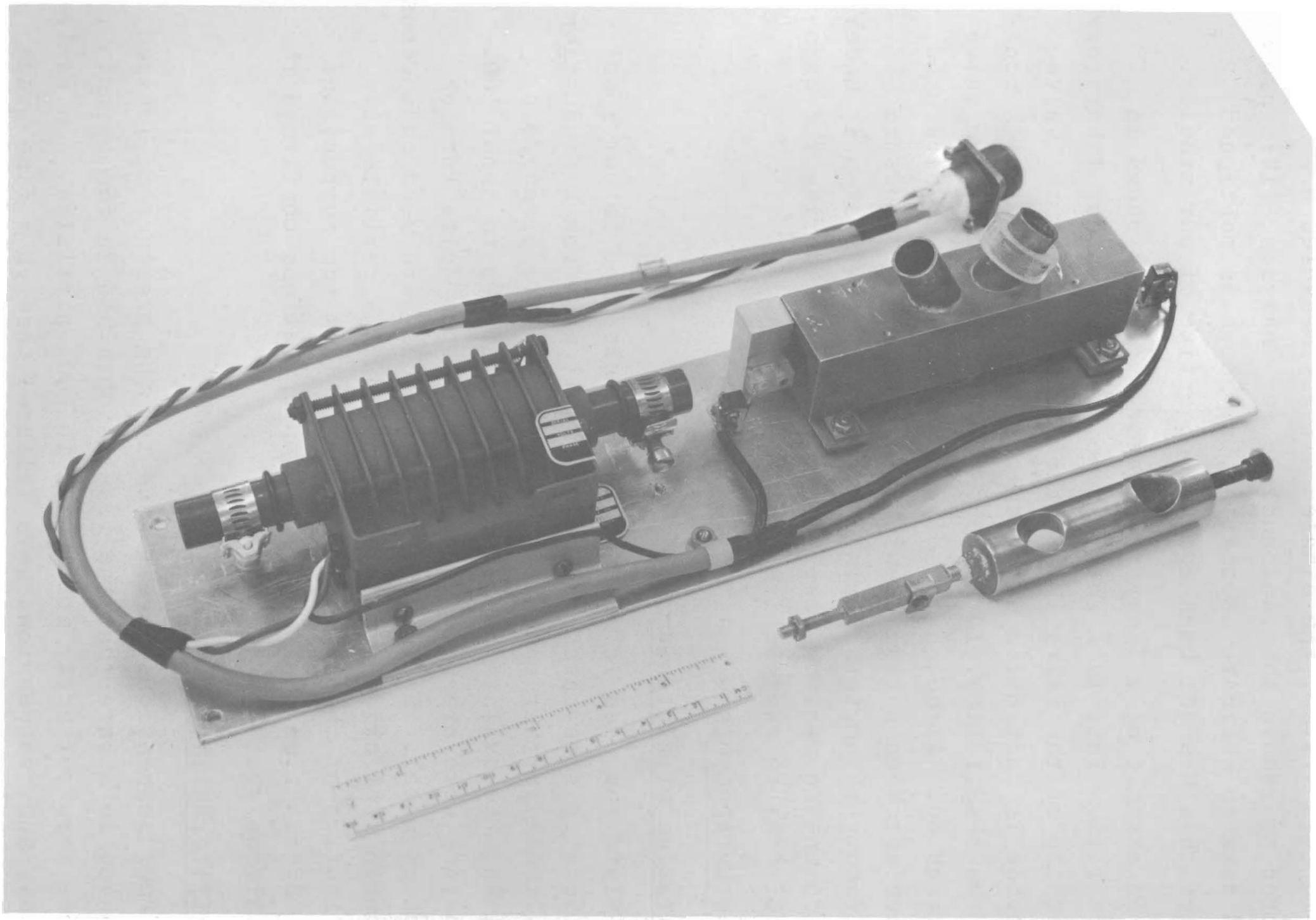

Neg 38997-5

FIGURE 1.14. Three-Way Respiratory Valve Showing Linear Motor 
In this system, the exhaled air was measured and also filtered to remove the radionuclide for analyses. This provided data to estimate deposition, although as mentioned earlier this has not been a major objective of our studies.

An example of a 3-way respiratory valve is shown in Figure 1.15. This is a rotary type designed in our laboratory. At the top of the valve is a motor which actuates the valve. The motor is controlled electronically by a system which monitors the respiration of the dog. Figure 1.16 shows the valve disassembled. Although this is one of the best we have used, we have not been satisfied with the technique to measure respiratory parameters during exposure. A new system is under development to monitor respiratory excursions during the exposure of dogs to radioactive aerosols.

PLUTONIUM AEROSOLS

Preparation of Plutonium

Plutonium used in our studies was prepared to our specifications in some cases and in others it was from a production run without further manipulation. Oxides were prepared by calcining the oxalate at temperatures from 300 to about $1000{ }^{\circ} \mathrm{C}$. Two oxides were prepared by oxidation of the delta form of plutonium metal. Sedimentation techniques were used on aqueous suspensions of oxide particles to narrow the particle size distribution of the aerosols generated from the suspensions. $X$-ray diffraction analyses of $\mathrm{PuO}_{2}$ preparations confirmed the crystalline state.

\section{U1trafilterability Tests}

$\mathrm{PuO}_{2}$ suspensions were tested for the presence of ionized plutonium to assure that the results obtained in the animal studies were correctly attributed to $\mathrm{PuO}_{2}$ particles. In early studies, $\mathrm{PuO}_{2}$ suspensions were filtered through a fine-grade 


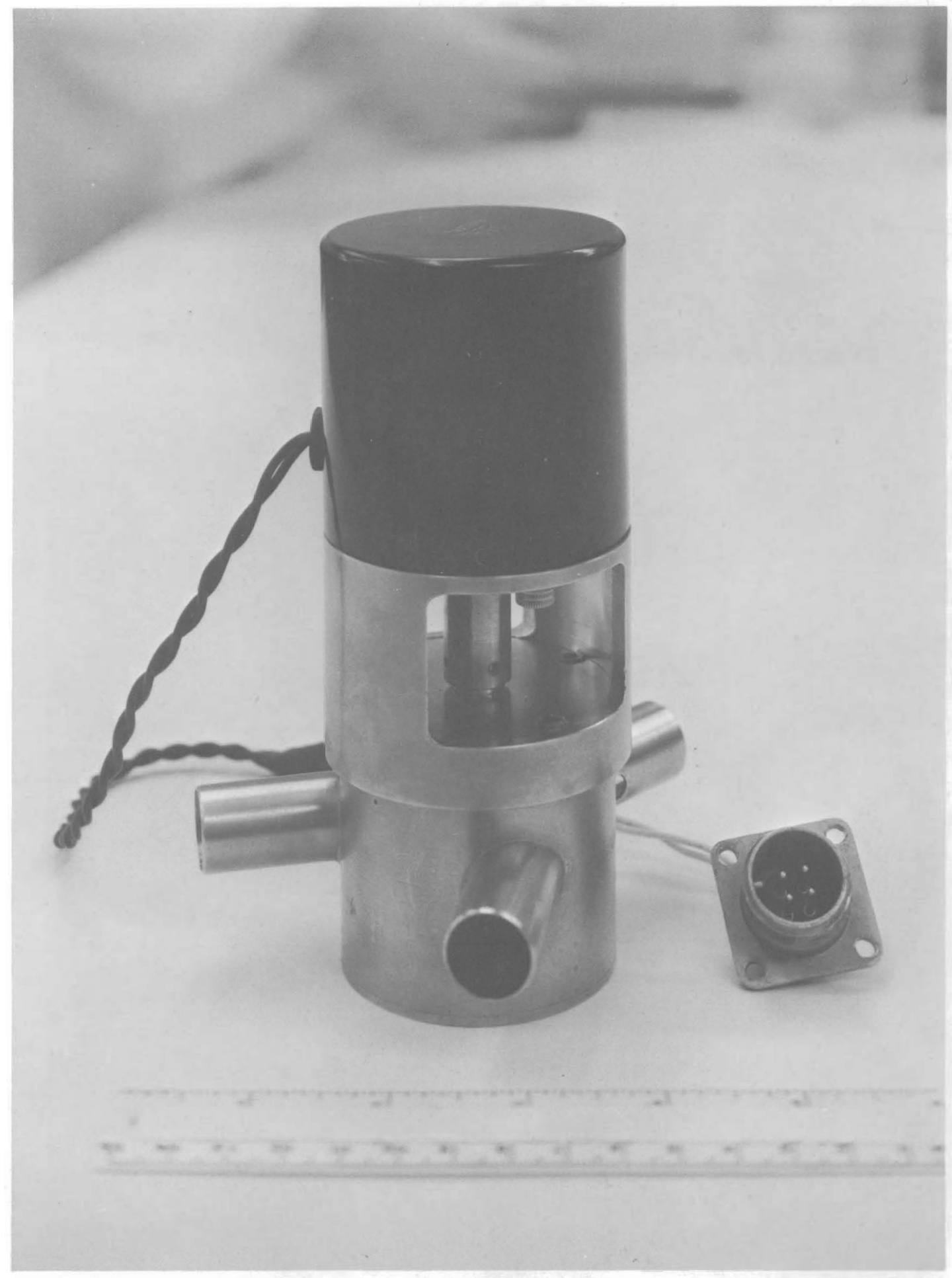

Neg 38997-2

FIGURE 1.15. Rotary Type Three-Way Respiratory Valve for Exposure of Dogs to Radioactive Aerosols 


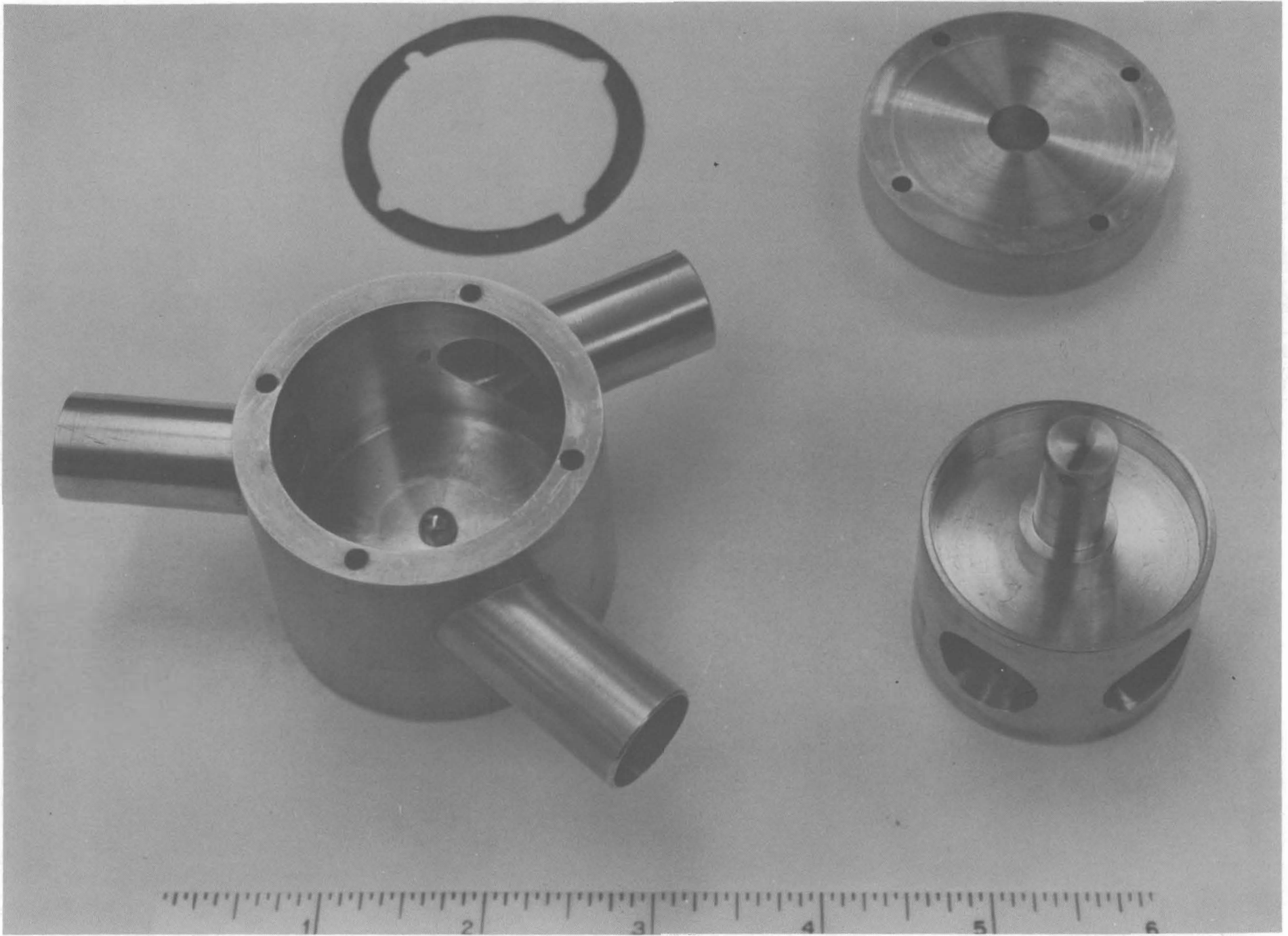

Neg 38997-1

FIGURE 1.16.

Rotary Type Three-Way Respiratory Valve for Exposure of Dogs to Radioactive Aerosols - Disassembled 
membrane filter having an average pore size of $0.3 \mu \mathrm{m}$. The filter was expected to retain all particles larger than $0.005 \mu \mathrm{m}$ with at least $95 \%$ efficiency.

More recently, the method of Lindenbaum and Westfall has been used to test the ultrafilterability of plutonium particle suspensions. By this method the plutonium suspension in a dialysis bag is centrifuged at $1000 \times$ gravity for 40 minutes. The plutonium in the ultrafiltrate passing through the dialysis membrane having an average pore size of $24 \AA$ is measured.

We routinely test the integrity of the membrane with a hemoglobin solution. The hemoglobin molecule, about $70 \AA$ by $40 \AA$, should not pass the dialysis membrane with a pore size of $24 \AA$. Hemoglobin in the ultrafiltrate is taken as evidence for a disrupted membrane. In our tests hemoglobin was added to the plutonium suspensions in the dialysis tubing before centrifugation. Hemoglobin was found in the ultrafiltrate from ${ }^{238} \mathrm{Pu}$ suspensions with a higher frequency than from ${ }^{239} \mathrm{Pu}$ suspensions. Also, in some cases we found that the fraction of plutonium in the ultrafiltrate increased with the amount of plutonium placed in the dialysis tubing. Some of these results are shown in Table 1.3. The amount of plutonium in the ultrafiltrate varied by a factor of 10 depending upon the amount of plutonium placed in the dialysis tubing. In a number of these there was evidence of hemoglobin. Therefore, we suspect that plutonium may in some cases alter the pore size of the dialysis membrane.

Generation of Aerosols

Plutonium aerosols have been produced from dry powder or from suspensions and solutions. Because the mass of material is small, conventional aerosol-generating systems such as dust mills cannot be used. Therefore, new or modified methods were required. 
TABLE 1.3. Ultrafilterability of Plutonium Solutions and Suspensions

\begin{tabular}{|c|c|c|c|c|}
\hline Compound & $\begin{array}{c}\text { Concentration, } \\
\mu \mathrm{Ci} / \mathrm{m} 1\end{array}$ & $\begin{array}{l}\text { Particle Size } \\
\text { CMD, } \mu \mathrm{m} \\
\end{array}$ & \multicolumn{2}{|c|}{$\begin{array}{r}\text { Percent } \\
\text { Filtered } \\
\end{array}$} \\
\hline${ }^{239} \mathrm{Pu}\left(\mathrm{NO}_{3}\right)_{4}$ & 400 & --- & & 10 \\
\hline $239 \mathrm{PuO}_{2}$ & 40 & 0.05 & & 1.5 \\
\hline & 3 & 0.05 & & 0.15 \\
\hline${ }^{239} \mathrm{PuF}_{4}$ & 40 & $\sim 0.2$ & 0.2 & -1 \\
\hline & 20 & $\sim 0.2$ & 0.2 & -0.7 \\
\hline${ }^{238} \mathrm{PuO}_{2}$ (P1asma Torch) & 500 & 0.04 & & 2 \\
\hline & 100 & 0.04 & & 0.5 \\
\hline${ }^{238} \mathrm{PuO}_{2}\left(300^{\circ}\right)$ & 1500 & 0.06 & 1 & -2.5 \\
\hline & 400 & 0.06 & 1 & -2 \\
\hline${ }^{238} \mathrm{PuO}_{2}\left(750^{\circ}\right)$ & 500 & 0.04 & & 1 \\
\hline
\end{tabular}

\section{Dispersion of Solutions and Suspensions}

A modified Laterbach-type generator was used for dispersion of solutions and suspensions. The aerosol generator was constructed from 1-in. OD plastic pipe or from an 8-in. long, 1-in. plastic rod with a 3/4-in. hole drilled from one end to within $1 / 2$ in. of the other end (Figure 1.17). A side arm was attached near the open end to lead the aerosol into the aerosol chamber. A length of $1 / 4-i n$. stainless steel tubing sealed at the bottom end with the top end extending through a rubber stopper was inserted into the generator. One to seven very fine holes, drilled in the wall of the tubing about 1/4-in. from the scaled end, were located at the surface of the plutonium suspension or solution. Filtered dry air delivered at $30 \mathrm{psi}$ to the tubing produced a fog consisting of plutonium particles. This was directed into the aerosol chamber. 
BNWL - 1221

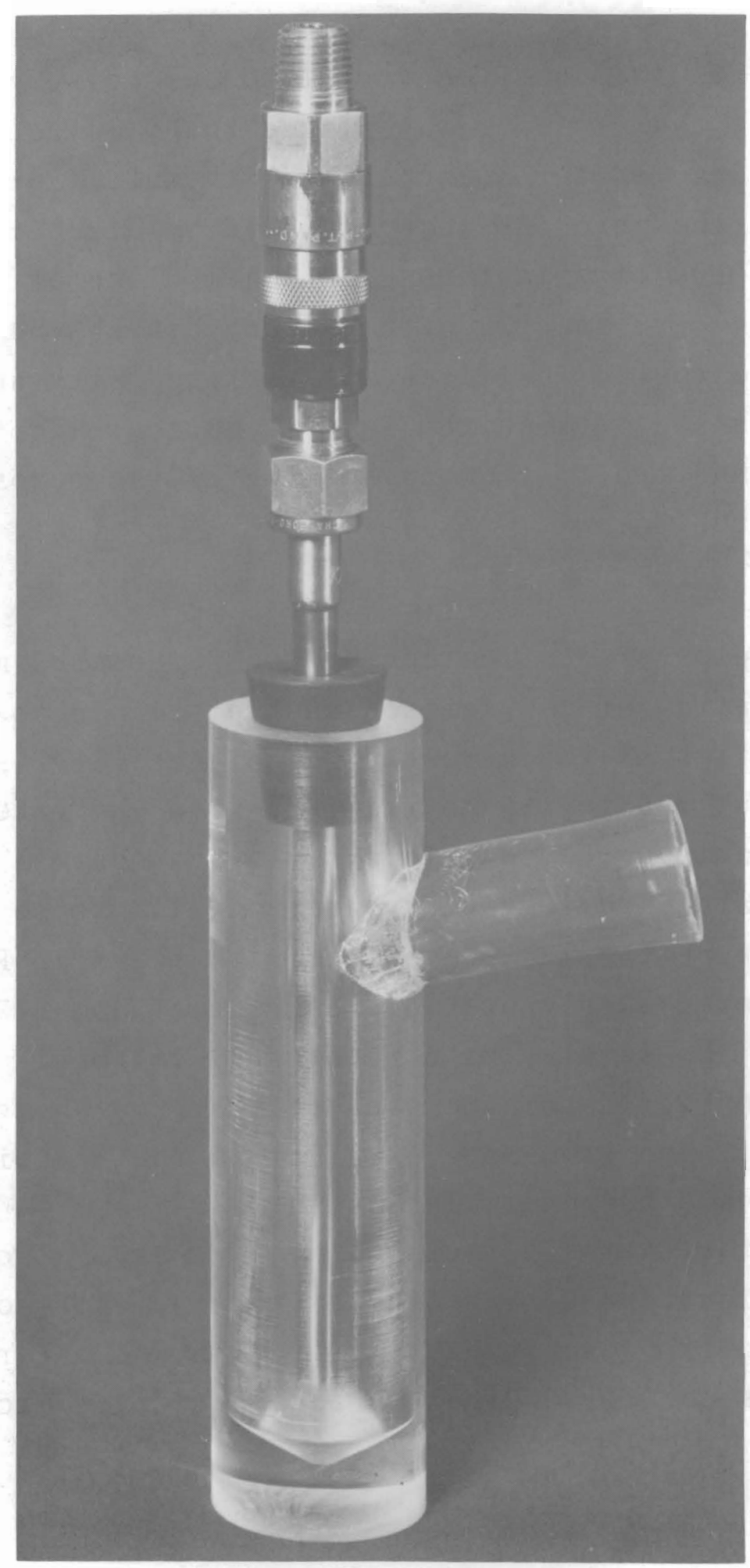

Neg 0690341-?

EIGURE 1.17. Aerosol Generator 
BNWL -1221

\section{Dry Dusts}

Aerosols were produced from dry plutonium dust by two methods. In one, the dry dust was placed in No. 4 gelatin capsules and fired into an aerosol chamber with an air pistol. In a second method, the aerosols were produced by directing dry air at $a^{-}$rate ${ }^{-}$of $100{ }^{-} \mathrm{cm}^{3} / \mathrm{min}^{-}$through a small diaméte tube attached as a side arm to a $25 \mathrm{ml}$ flask containing the dry plutonium dioxide dust. The flask was vibrated with an electric test tube shaker to keep the dust in motion. The top of the flask was connected to the top opening of the aerosol chamber by flexible tubing.

\section{Aeroso1 Samp1ing}

Aerosol samples are collected for two purposes: measuring average concentration of the aerosol and determining particle size characteristics of the aerosol. Membrane filter samples, collected at about 100 to $150 \mathrm{~cm}^{3} / \mathrm{min}$, provide estimates of the aerosol concentration. For particle sizing, a thermal precipitator collects samples directly on electron microscope grids. The Walkenhorst-type thermal precipitator is shown in Figure 1.18. The power supply provides current at about 2 A. Air is drawn through the sampler at a rate of $40 \mathrm{~cm}^{3} / \mathrm{min}$. Four electron microscope grids are mounted on platinum posts in each of the two plugs. The grids are parallel to the hot wire in the precipitator and perpendicular to the air flow. A membrane filter backs up the thermal precipitator. We have also used a point-to-plane electrostatic precipitator. The one shown in Figure 1.19 was designed at the University of Rochester. The aerosol sample is collected directly on an electron microscope grid.

Particle Sizing

The electron microscope grids are shadowed with chromium at an angle of about 20 degrees. The electron micrographs are 


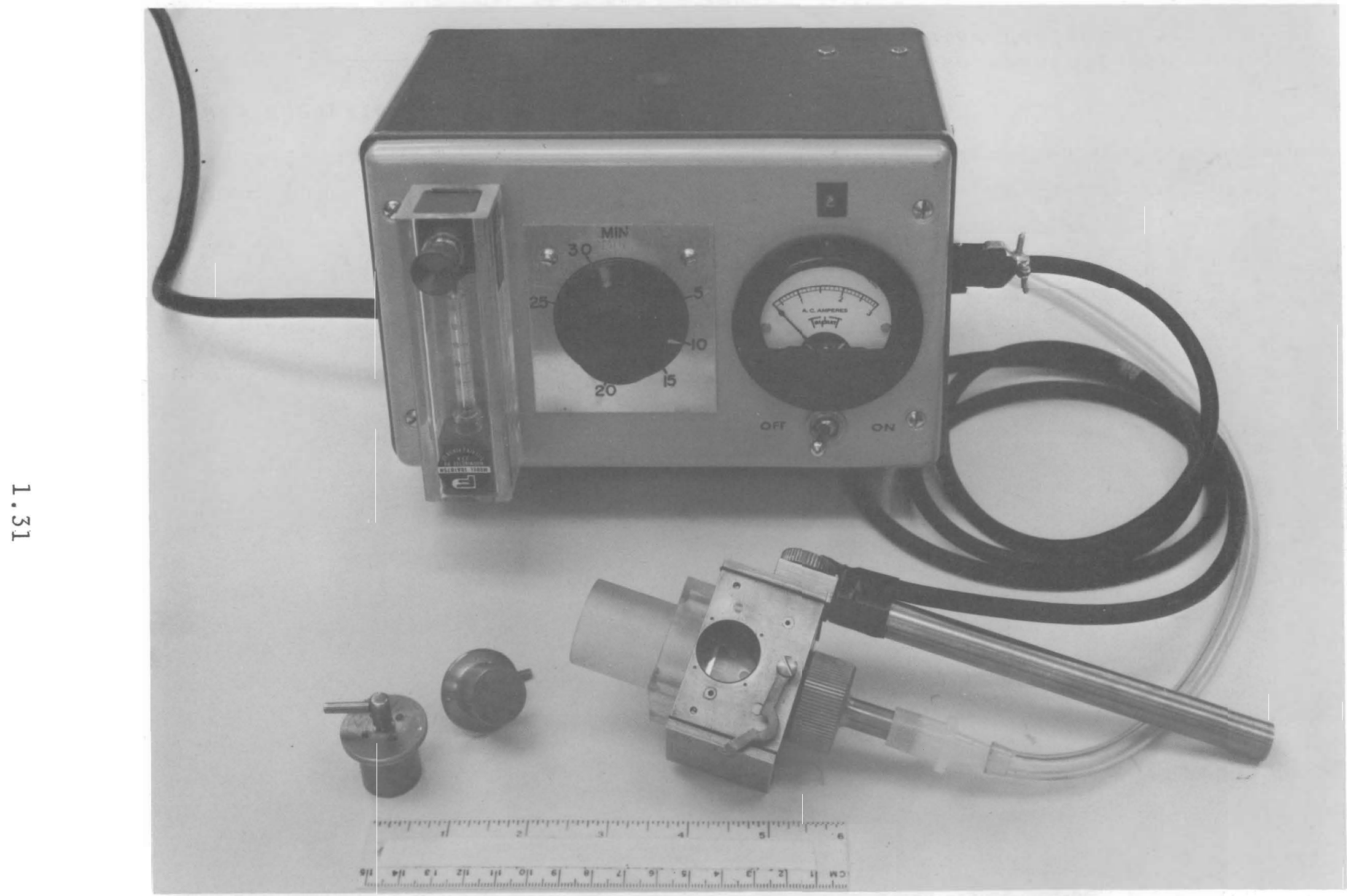

Neg 38997-4 


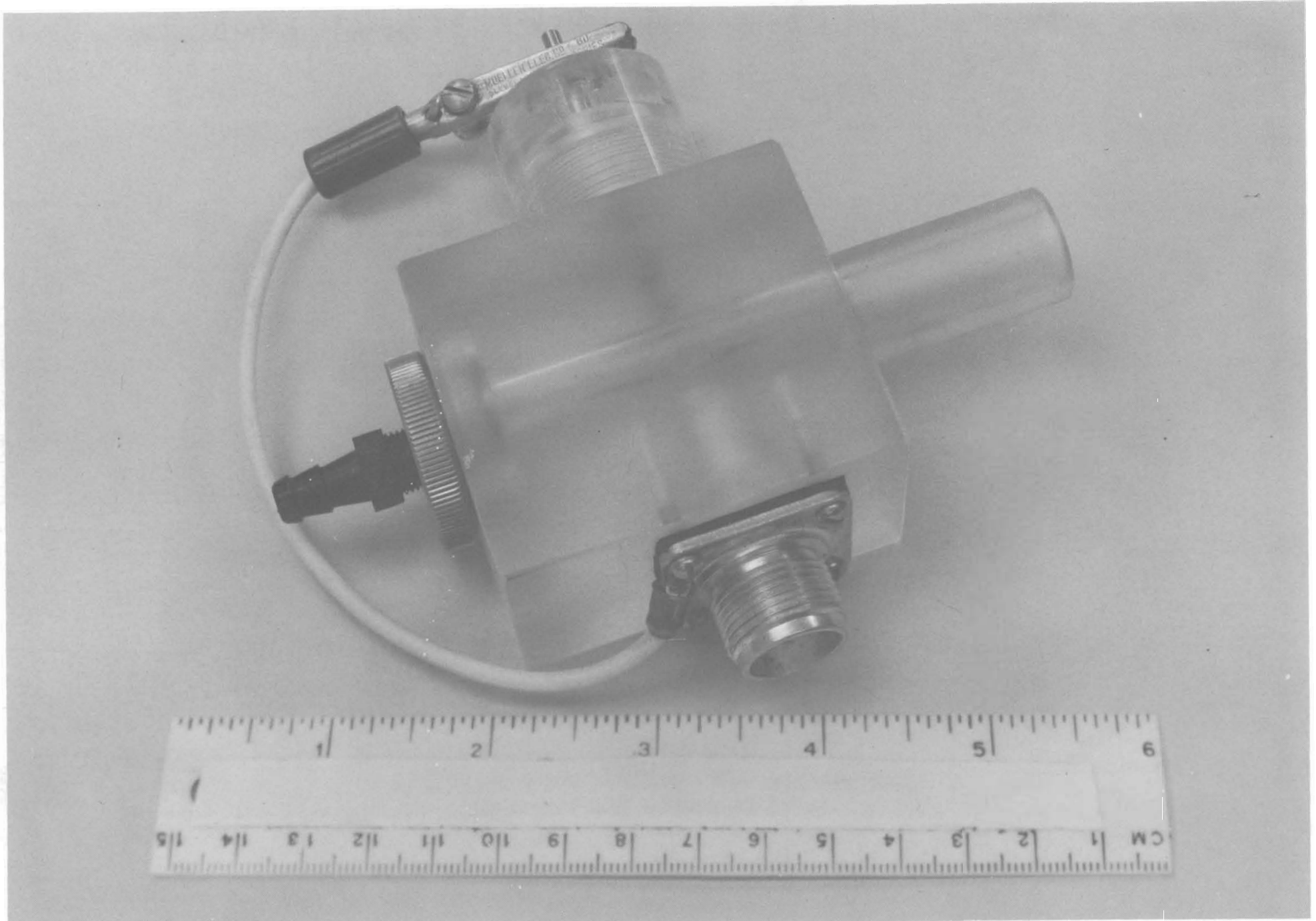

Neg 38997-14

FIGURE 1.19. Point-to-Plane Electrostatic Precipitator (from University of Rochester Design) 
made at a magnification of about 30,000. A Zeiss particle size analyzer is used to size the particles and the results are processed by a computer program to give several parameters of a log-normal distribution. These include:

- Geometric mean.

- Geometric standard deviation.

- Average diameters:

Count, specific surface, surface area, volume, volume/unit surface area.

- Median diameters:

Count, surface, mass.

Figure 1.20 is an electron micrograph of $\mathrm{PuO}_{2}$ particles with a CMD of $0.6 \mu \mathrm{m}$ and MMD of $4.3 \mu \mathrm{m}$. The third dimension, height, of the particle is indicated by the length of the shadows .

Figure 1.21 is an electron micrograph of $\mathrm{PuO}_{2}$ particles with a CMD of $0.05 \mu \mathrm{m}$ and MMD of $0.12 \mu \mathrm{m}$.

The $\mathrm{PuO}_{2}$ particles have a density of about 11 and are essentially opaque to the electrons. However, there is always a degree of uncertainty about whether all the particles sized are $\mathrm{PuO}_{2}$ or some contaminating dust. Therefore, a technique was developed to examine autoradiograms of aerosol samples with the electron microscope. Figure 1.22 is an example. Particles from which alpha tracks originated can be identified as being plutonium. There were particles in this sample which were not plutonium, although they were dense particles.

\section{IN VIVO MONITORING}

We have used in vivo monitoring techniques in our plutonium studies since 1956. Because in vivo counting of plutonium is subject to errors, we have not always been willing to accept the results in a quantitative sense. However, in vivo counting has been extremely useful to the investigator 


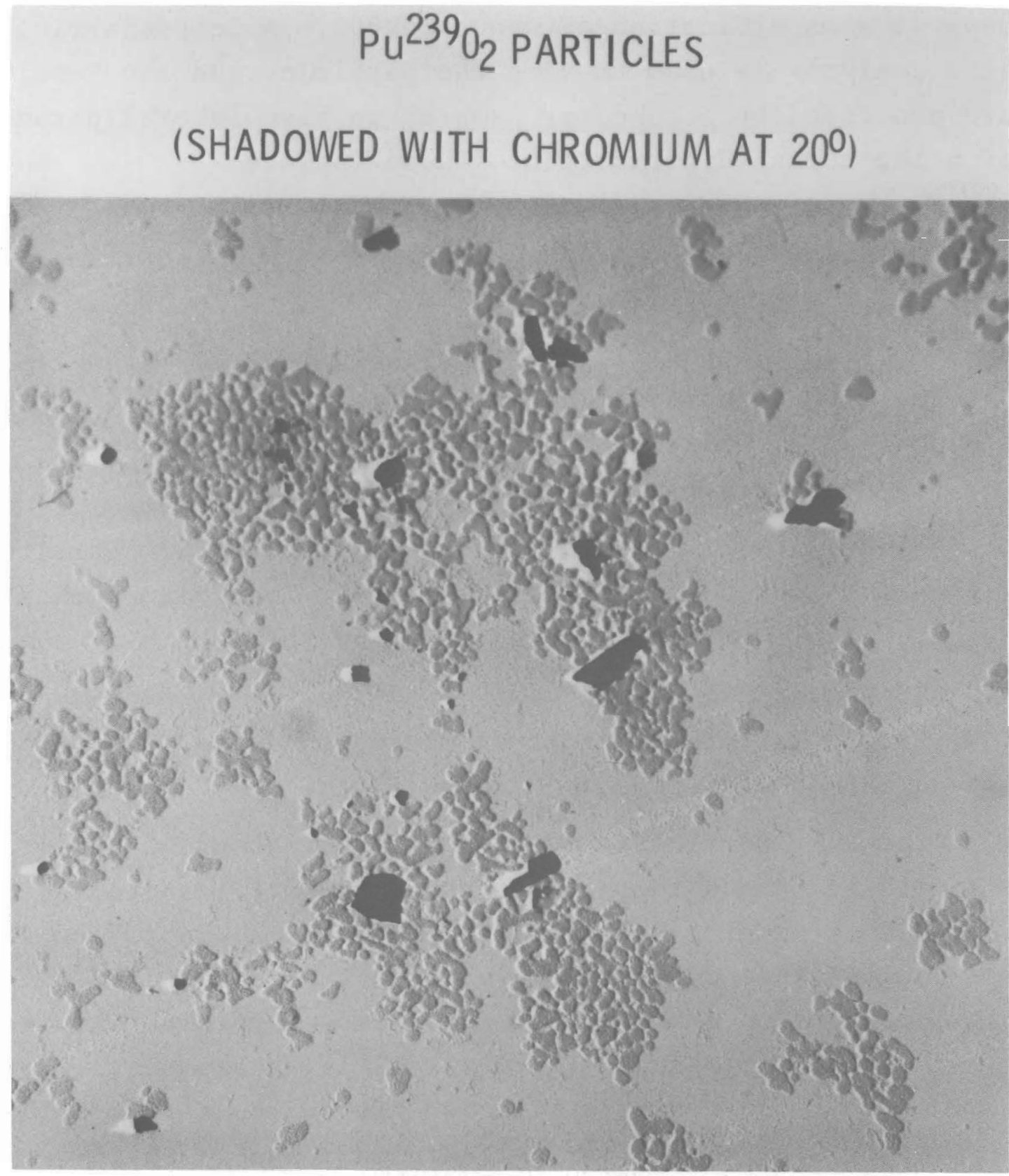

\section{$1 \mu$}

Neg $062519-14$

FIGURE 1.20. Electron Micrograph of PuO 2 Particles (Count median diameter $=0.6 \mu \mathrm{m}$ ) 


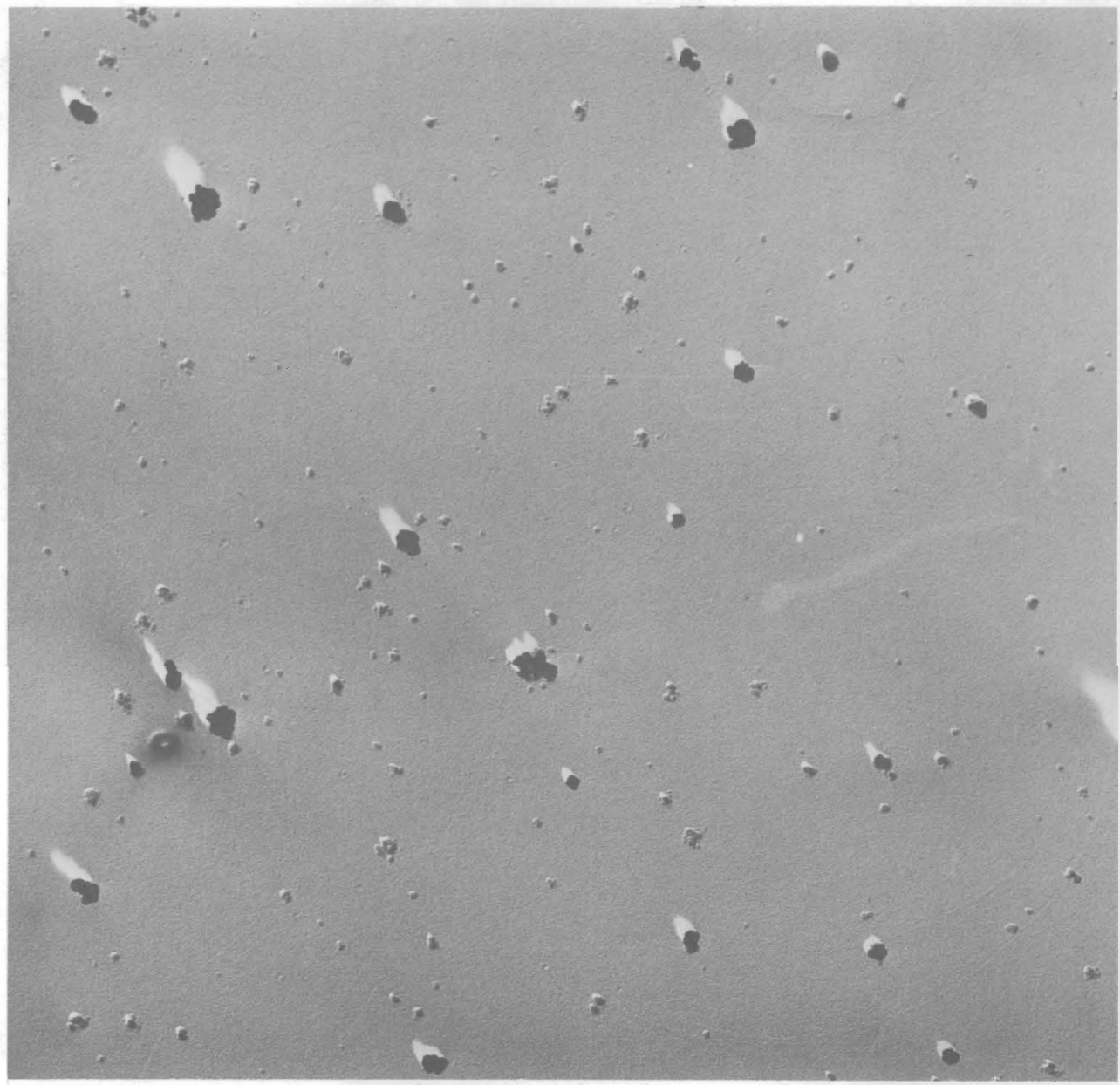

FIGURE 1.21. Electron Micrograph of PuO 2 Particles (Count median diameter $=0.05 \mu \mathrm{m}$ ) 

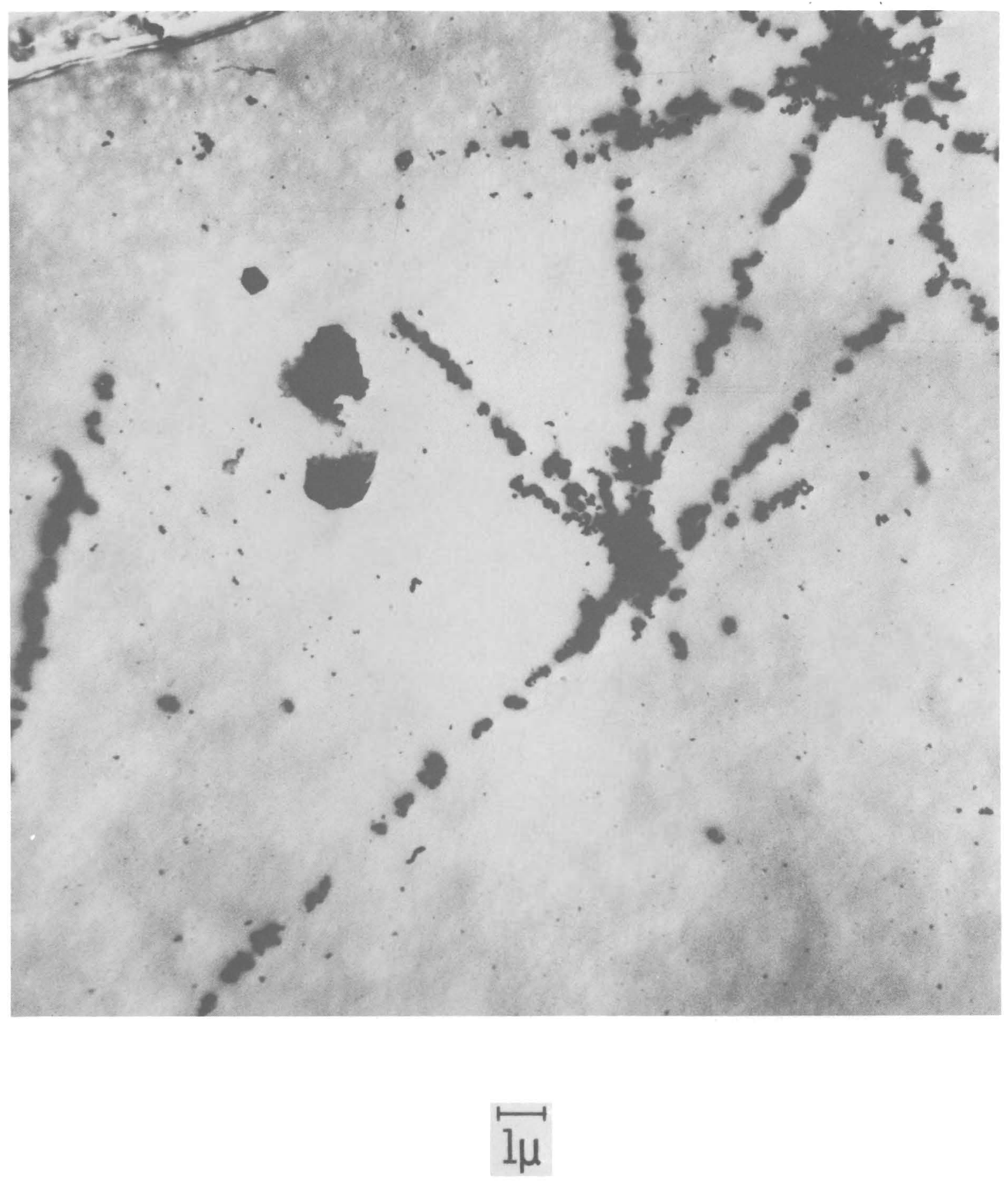

Neg 062519-16

FIGURE 1.22. EZectron Micrograph of an Autoradiogram of $239 \mathrm{PuO}_{2}$ Particles 
in a qualitative sense in following the progress of a given experiment. With constant careful recalibration the results can be very reliable, especially in rodents.

Figure 1.23 shows a whole body counting assembly for rodents. The cast lead shield housed three $1 \mathrm{~mm} \times 2$ in. NaI (Th) crystals and the photomultiplier tube assemblies. The horizontal animal tunnel was $2-1 / 2$ in. in diameter to admit rats placed in 7 -in. long perforated cardboard cylinders. Signals from three detectors were integrated into a singlechannel pulse height analyzer with a window of 14 to $43 \mathrm{keV}$. This instrument is used for both ${ }^{238} \mathrm{Pu}$ and ${ }^{239} \mathrm{Pu}$. The $17 \mathrm{keV}$ $\mathrm{X}$ rays from ${ }^{239} \mathrm{Pu}$ and the attenuated $43 \mathrm{keV}$ gammas from ${ }^{238} \mathrm{Pu}$ are detected. Frozen rats containing known amounts of ${ }^{238} \mathrm{Pu}$ or ${ }^{239} \mathrm{Pu}$ are used for calibration. Figure 1.24 shows the energy spectra obtained for ${ }^{238} \mathrm{Pu}$ and ${ }^{239} \mathrm{Pu}$.

With this instrument, a counting rate of $1000 \mathrm{cpm}$ is equivalent to $0.16 \mu \mathrm{Ci}$ of ${ }^{239} \mathrm{Pu}$ or $0.095 \mu \mathrm{Ci}$ of ${ }^{238} \mathrm{Pu}$. An example of a plutonium retention curve obtained for a rat is shown in Figure 1.25. The data are adequate for determining the retention half time and other parameters.

The rodent counter can be used to obtain longitudinal scans of the animals by adjusting the shield so that the crystals monitor only a fraction of the animal at one time. The animal is then moved through the counter at a predetermined rate.

A dog counter was developed along the same general design as the rodent counter, except that the whole dog could not be monitored at once, but had to be scanned. The instrument is shown in Figure 1.26. The crystal detectors are mounted in the shadow shield. Three of the five crystals surrounding the dog in a vertical plane are 2 in. $x 2$ in. NaI (T1) and two are $1 \mathrm{~mm} \times 2$ in. crystals. The two thin crystals, mounted opposite 


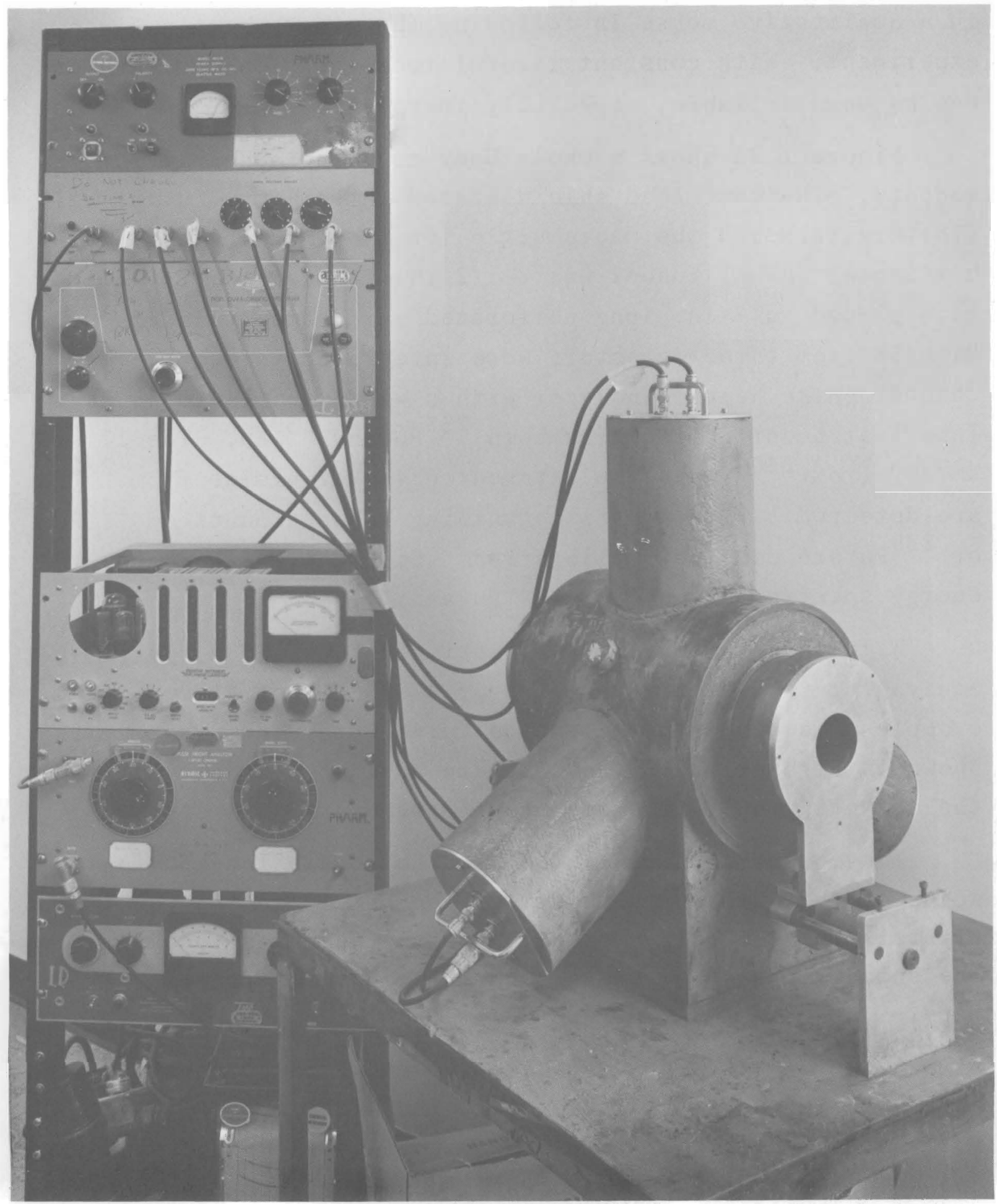

Neg $0690341-5$

FIGURE 1.23. Whole Body Counting Assembly for Rodents 


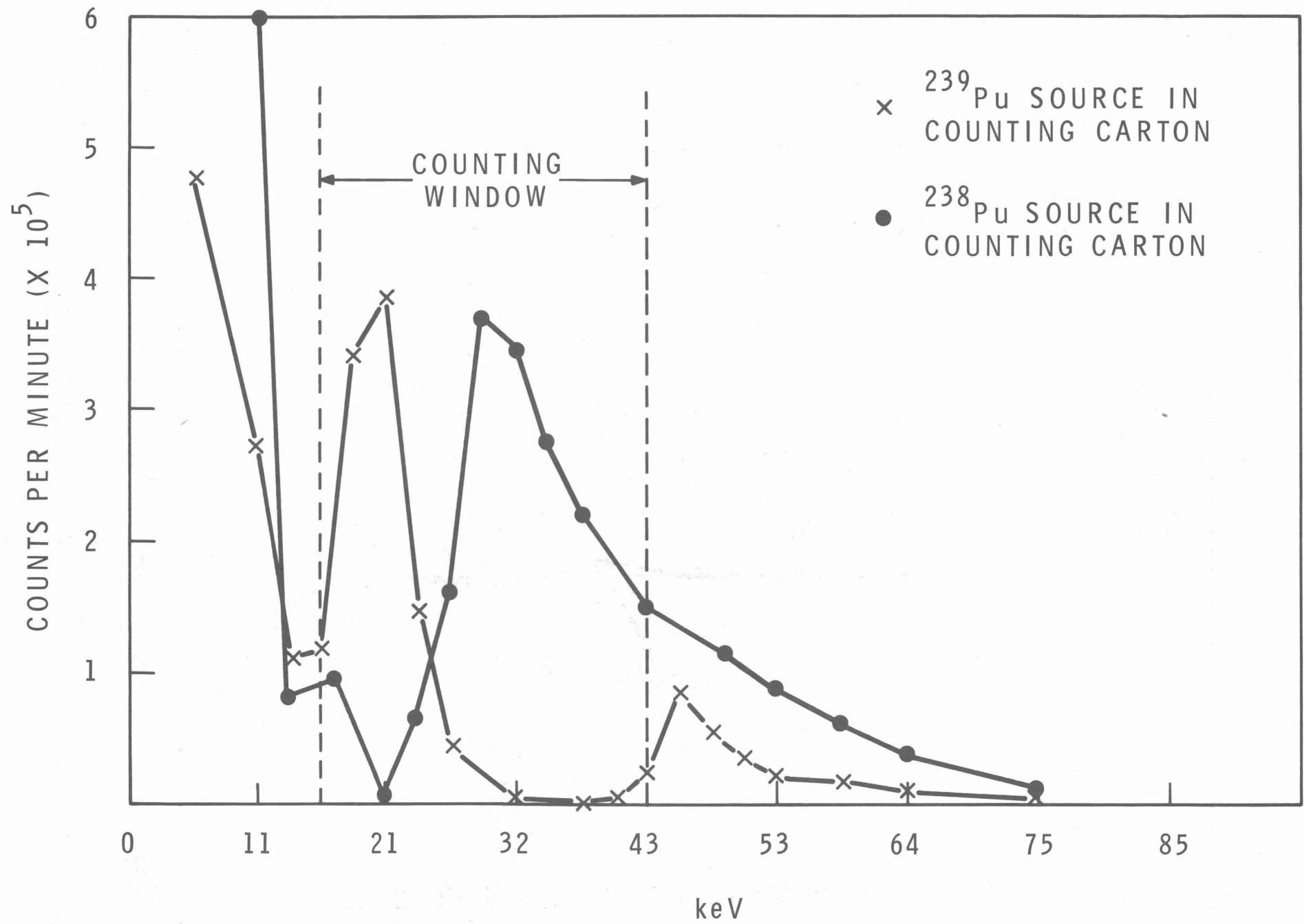

Neg 0681972-8

FIGURE 1.24. X-ray and Gamma Energy Spectra of ${ }^{238}$ Pu and ${ }^{239}$ Pu Sources 


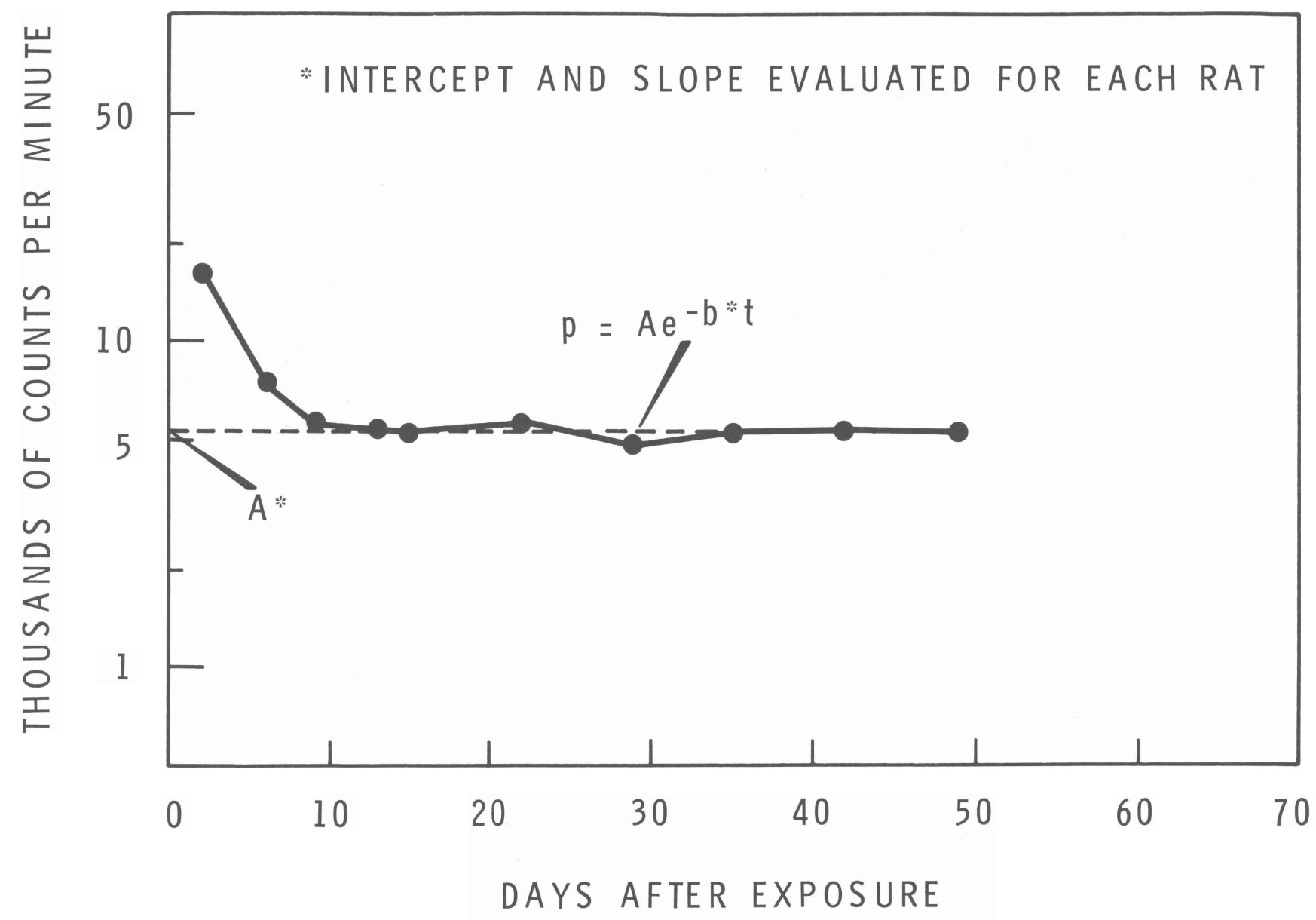

Neg $0681972-7$

FIGURE 1.25. Typical Whole Body Retention Curve for Inhaled Plutonium oxide in Rats (Initial alveolar deposition is taken as value of intercept of retention curve on ordinate.) 


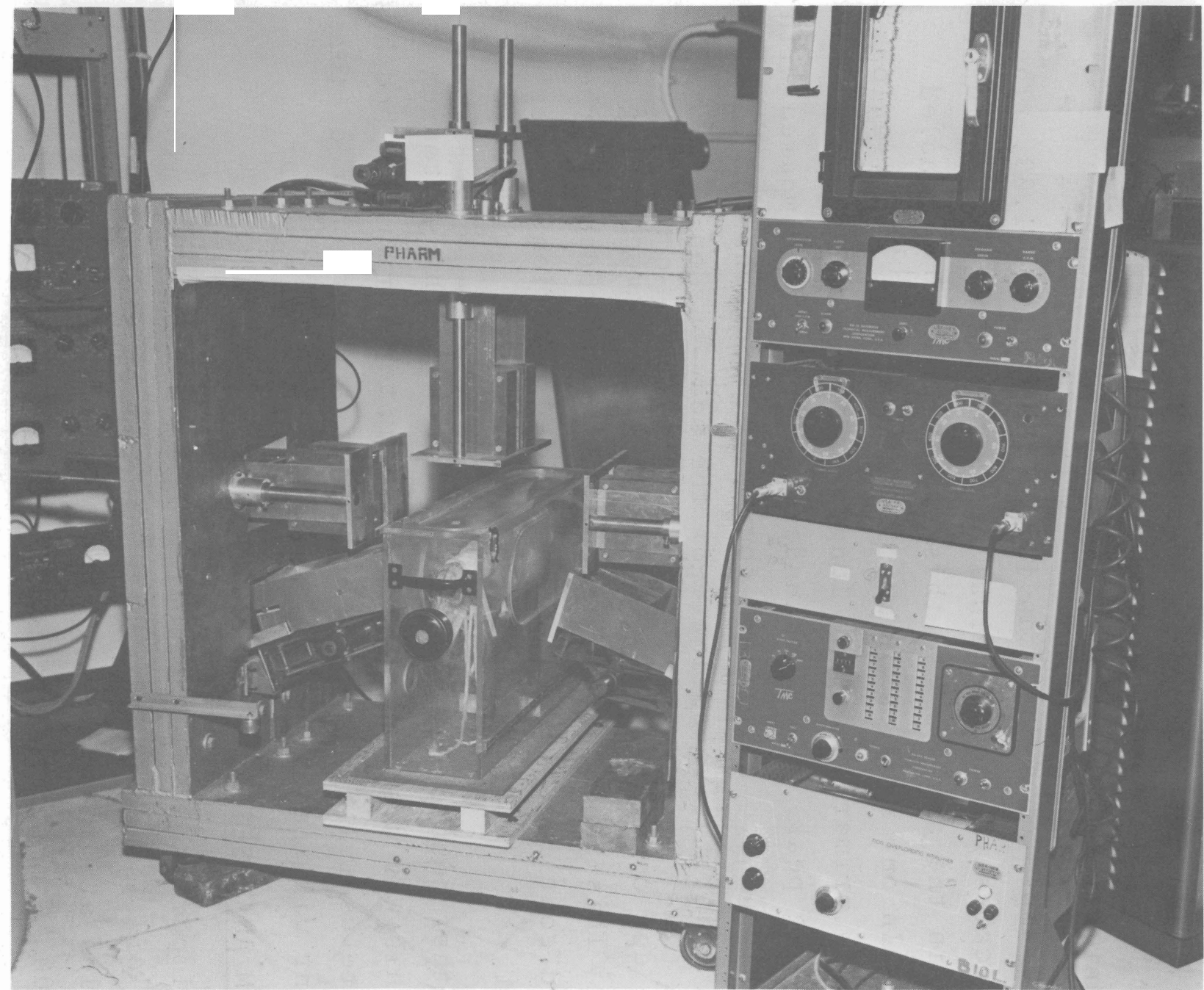

Neg 29715-12

FIGURE 1.26.

Whole Body Longitude Scanning System for Detecting Radionuclides in Dogs 
each other, are used for plutonium while the three thick crystals are used for gamma emitters. The crystals are enclosed in lead collimaters which assure that the crystals monitor only a small volume of the dog. The dog is propelled past the detectors on a motor-driven cart at a constant rate (Figure 1.27). For counting, the dog is restrained in a counting box as shown in Figure 1.28. This holds the dog in a constant position.

An example of a dog scan is shown in Figure 1.29. The scan indicates the longitudinal distribution of the radioactivity in the animal. In this case the dog had inhaled ${ }^{59} \mathrm{Fe}_{2} \mathrm{O}_{3}$. In our studies of insoluble compounds, the radioactivity is primarily in the lung, and this scan shows a typical lung peak. The area under the curve is compared with that obtained with a standard source in a dog phantom to obtain a quantitative estimate of the body burden.

The dog counter is also used for in vivo monitoring of rodents. This is shown in Figure 1.30. The rodent in the cardboard container is placed in a fixed position between the crystals.

Another counter is also used for monitoring plutonium in dogs. This was designed as a chest counter for humans and has been quite useful for monitoring dogs. A description of this instrument will be given in a later lecture.

\section{PLUTONIUM ANALYSES}

An important aspect of our program is the plutonium analyses of tissues and excreta. The first step is drying of the samples at 150 degrees. Then the samples are muffled at 450 to $500{ }^{\circ} \mathrm{C}$ until the residues are carbon free. This may require alternate nitric acid wet ashing and muffling to produce carbon free residues. The residues are dissolved with $2 \mathrm{M} \mathrm{HNO}_{3}$ and $5 \% \mathrm{HF}$ evaporated to dryness at $150{ }^{\circ} \mathrm{C}$, redissolved 
BNWL - 1221

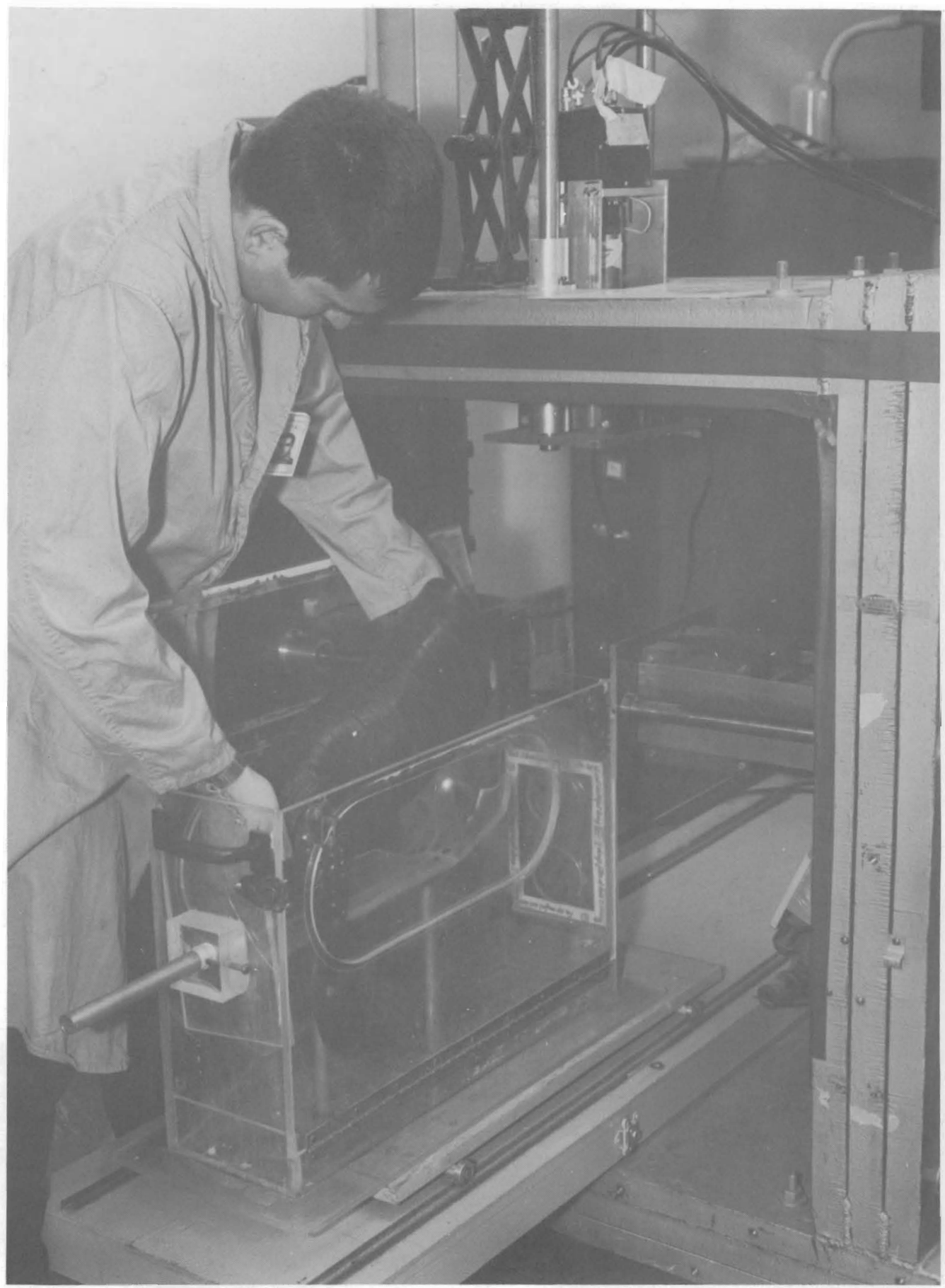

Neg 0690341-9

FIGURE 1.27. Whole Body Longitude Scanning System for Detecting Radionuclides in Dogs (Transport system for propelling dog scintillation crystals mounted in iron shield.) 


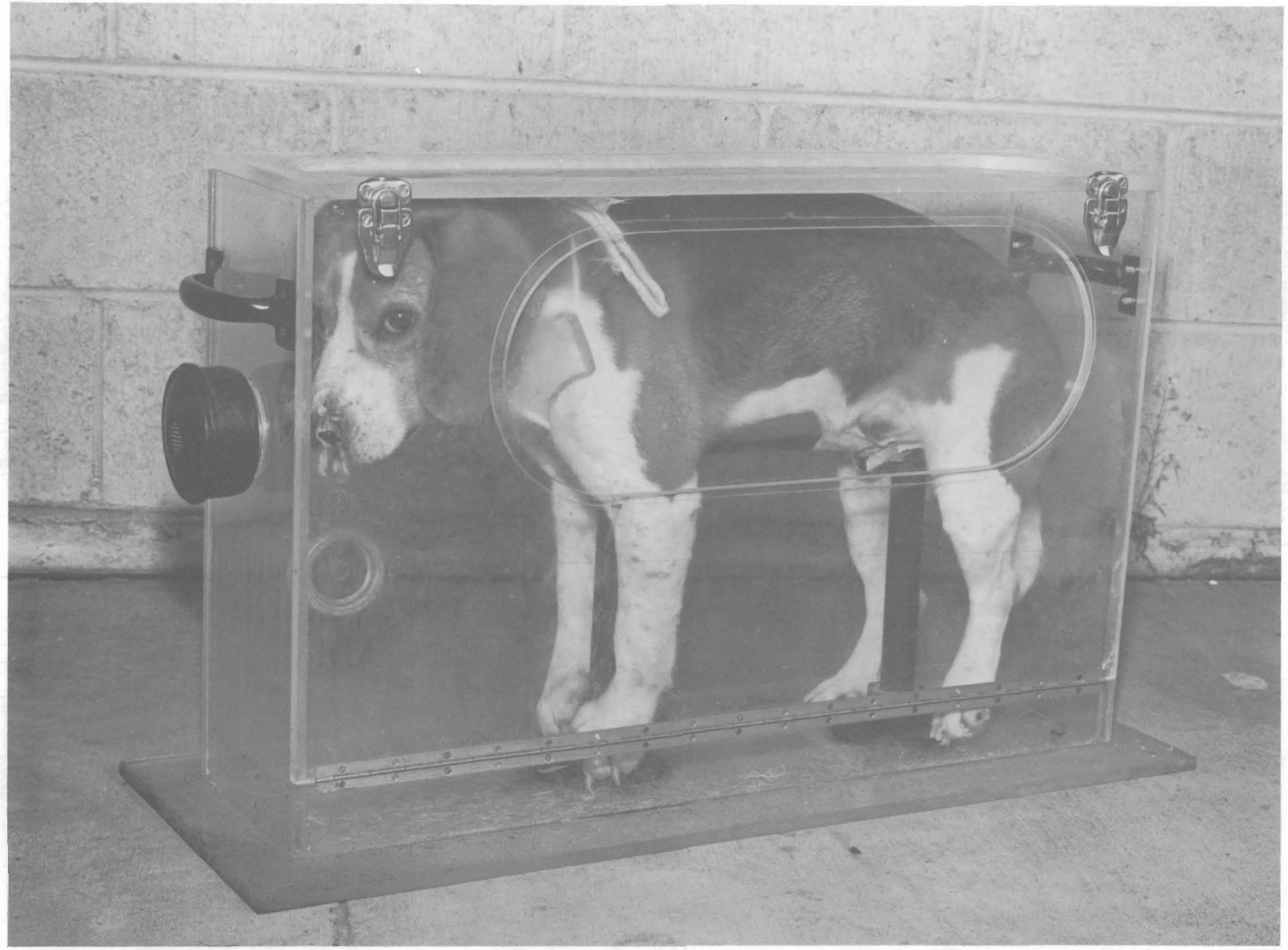

Neg 29715-3

FIGURE 1.28. Plastic Box Used to Contain Dogs for Counting 
BNWL - 1221
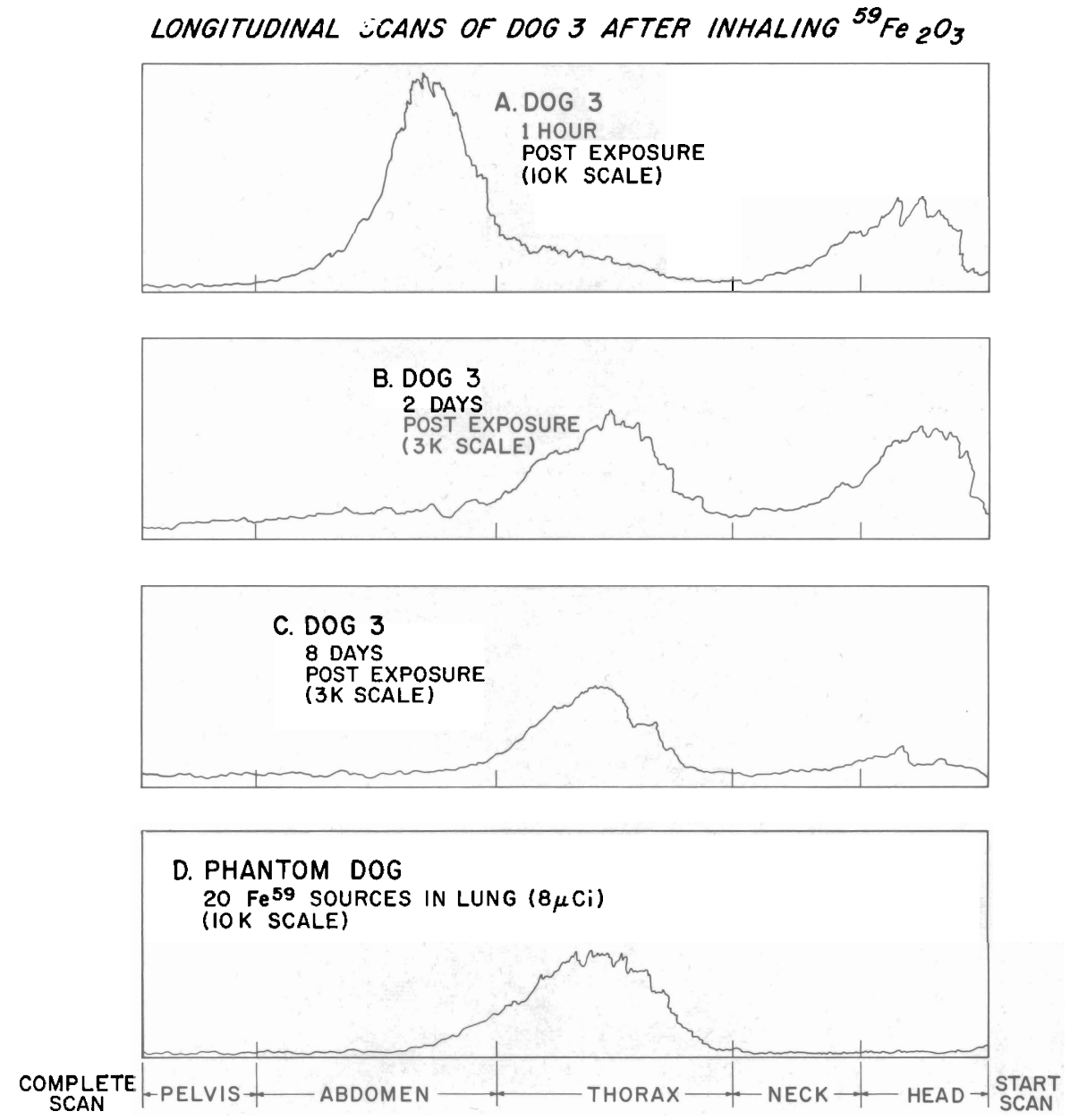

\section{Neg 0651463-1}

FIGURE 1.29. Examples of Longitudinal Scans of Dogs 


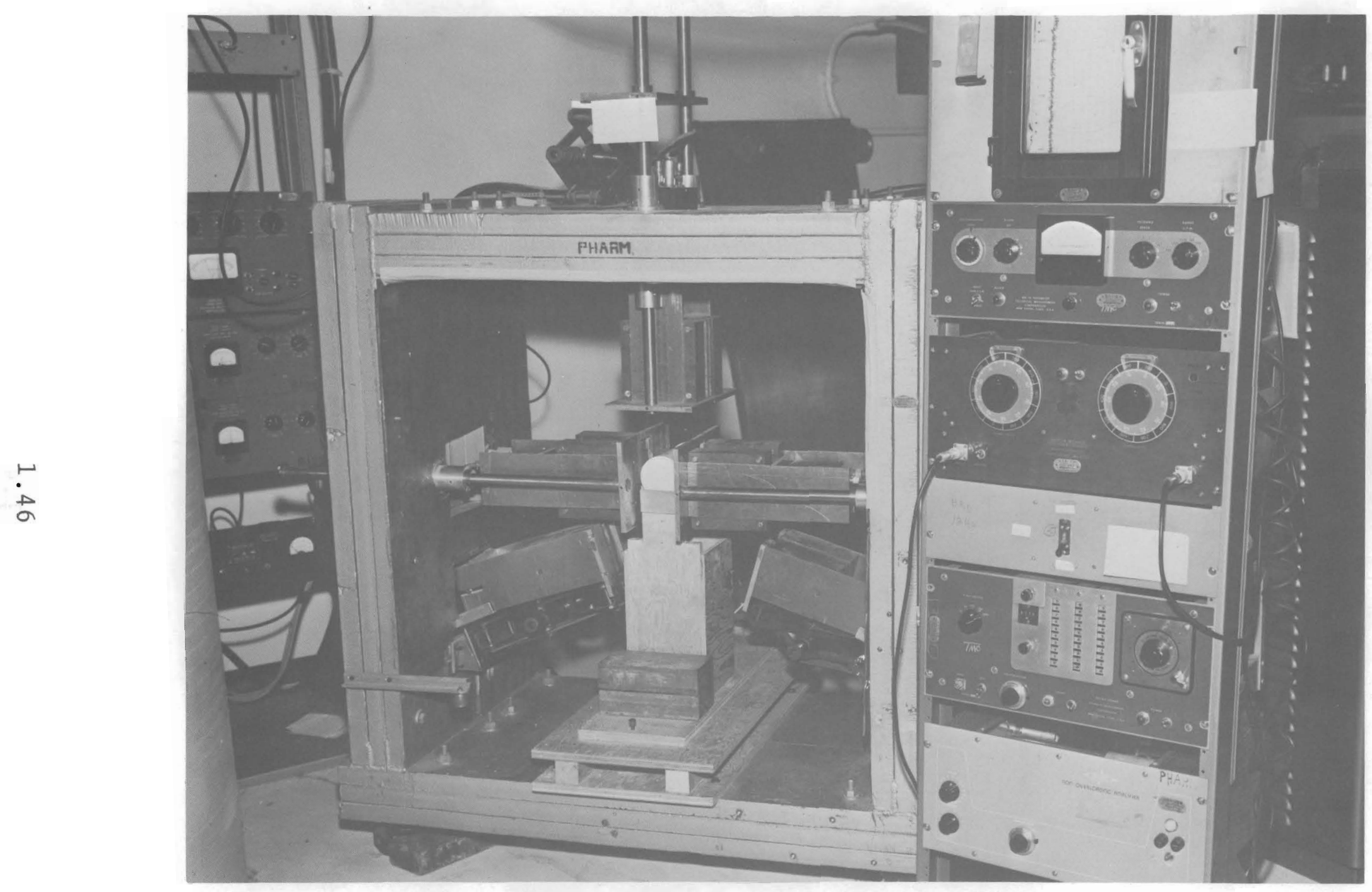

Neg 29715-1

FIGURE 1.30. Adaptation of the Dog Counter for Counting Rodents

(The rodents are contained in cylindrical cardboard cartons.) 
with nitric acid and evaporated at $300^{\circ} \mathrm{C}$. It is finally dissolved in $2 \mathrm{M}^{-} \mathrm{HNO}_{3}+1 \% \mathrm{H}_{3} \mathrm{BO}_{3}$, treated with urea, and extracted with the $\mathrm{D}_{2}$ EHPA [bis(2-ethylhexyl) hydrogen phosphate] scintillating solution. Measurements are made by liquid scintillation counting. A preliminary concentration by coprecipitation with lanthanum fluoride or bismuth phosphate is useful for samples in which the plutonium content approaches background levels.

The results of the plutonium analyses, the weights of tissues and excreta samples, and other pertinent data provide the input for a computer program which performs all calculations required to convert the data into a form for interpretation.

\section{SUMMARY}

We have gained enough experience through the years to standardize most of the procedures used in our plutonium studies. However, we are continually searching for better methods to improve our experiments, both quantitatively and qualitatively. Studies with plutonium are expensive and time consuming. Therefore, it is imperative to gain as much information as possible from each experiment. Subsequent lectures will summarize the results of our studies and indicate where additional information is needed to complete our knowledge of inhaled plutonium. 